\title{
Internal melting and ice accretion at the bottom of temperate glaciers
}

\author{
L. LLIBOUTRY \\ 3 Avenue de la Foy, 38700 Corenc, France
}

\begin{abstract}
Temperate glacier ice is neither dry nor impermeable, as the standard theory of glacier sliding assumes. This fact leads to the already published concept of locally stress-controlled temperatures. Why the temperature is determined by the highest principal pressure, why the microscopic stress equals more or less the macroscopic one, and why water may flow in the capillary network even when water lenses at grain boundaries are freezing is explained. The new concept is applied to ice sliding on a hard bed having a sine profile, without cavitation. First, the stress field for a Newtonian viscous material and a vanishing roughness are used; next, an improved one, that takes into account the non-linear viscosity of ice and the finite amplitude of the micro-relief. It appears that water migrates from the stoss sides of the bumps to the lee sides within a bottom layer of thickness $h_{\mathrm{w}}$. Moreover, there is less ice melting at the sole on the former ones than ice accretion on the latter, a fact that yields a trend of ice accretion at the glacier sole. It is balanced by internal melting near the bed and water oozing at the interface from the soaked ice. Consequintly, a thin layer of accreted regelation ice with a constant mean thickness $h_{\mathrm{i}}$ should exist at the interface. Modelling realistically mountain glaciers, $h_{\mathrm{w}} \sim 20 \mathrm{~cm}$ and $h_{\mathrm{i}} \sim 3.5 \mathrm{~cm}$ are found.
\end{abstract}

\section{NOTATIONS AND NUMERICAL VALUES FOR BLUE TEMPERATE ICE}

\section{Related to phase changes}

$A=\frac{K_{\mathrm{i}} C_{\mathrm{m}}}{\rho L}=0.0214 \mathrm{~m}^{2} \mathrm{MPa}^{-1} \mathrm{a}^{-1}$ : melting-refreezing

$C=2000 \mathrm{~J} \mathrm{~kg}^{-1} \mathrm{~K}^{-1}$ : thermal capacity of ice

$C_{\mathrm{m}}=\frac{T}{L}\left(\frac{1}{\rho}-\frac{1}{\rho_{\mathrm{w}}}+\nu R T\right)=\begin{aligned} & 0.098 \mathrm{~K} \mathrm{MPa}^{-1}: \text { lowering of } \\ & \text { melting point with pressure }\end{aligned}$

$C_{\mathrm{r}}=\frac{T \gamma}{L}\left(\frac{1}{\rho_{\mathrm{w}}}-\nu R T\right)=\begin{aligned} & 2.7 \times 10^{-8} \mathrm{~K} \cdot \mathrm{m}: \text { lowering of } \\ & \text { melting point with curvature }\end{aligned}$ $C_{\mathrm{s}}=\frac{R T^{2}}{L}=1.85 \mathrm{~K} \mathrm{~mol}^{-1} \mathrm{~kg}$ : lowering of melting point

$h_{\mathrm{i}}$ : mean thickness of the regelation ice layer

$h_{\mathrm{w}}$ : thickness of the ice layer allowing for water transfer from stoss sides to lee ones

$K_{\mathrm{b}}$ : thermal conductivity of bedrock

$K_{\mathrm{i}}=2.12 \mathrm{~J} \mathrm{~m}^{-1} \mathrm{~K}^{-1} \mathrm{~s}^{-1}$ : thermal conductivity of ice

$L \rho=306.4 \mathrm{MPa}$ : melting heat per unit volume

$r$ : freezing rate at the ice-bed interface

$R=8.3144 \mathrm{~J} \mathrm{~mol}^{-1} \mathrm{~K}^{-1}$ : gas constant

$T \approx 273 \mathrm{~K}$ : Kelvin temperature (or, in the second half of this paper, Celsius temperature)

$\gamma=0.034 \mathrm{~J} \mathrm{~m}^{-2}$ : energy of ice-water interface

$\kappa=K_{\mathrm{i}} / \rho C=1.16 \mathrm{~mm}^{2} \mathrm{~s}^{-1}=36.5 \mathrm{~m}^{2} \mathrm{a}^{-1}$ : thermal diffusivity $\nu$ : moles of air in air-saturated water per $\mathrm{kg}$ and per $\mathrm{Pa}$ $\rho=915 \mathrm{~kg} \mathrm{~m}^{-3}$ : ice density

$\rho_{\mathrm{w}}=1000 \mathrm{~kg} \mathrm{~m}^{-3}$ : water density

$\phi$ : heat flux

$\phi_{\mathrm{g}}$ : geothermal flux $\left(\phi_{\mathrm{g}} / \rho L \sim 1 \mathrm{~cm} \mathrm{a}^{-1}\right.$ in young mountains)

\section{Related to stresses}

$B=\frac{2 \dot{\epsilon}_{i j}}{\tau^{2} \tau_{i j}}=\underset{\text { parameter of creeping temperate ice }(w \text { is }}{200+368 w \pm 40 \mathrm{MPa}^{-3} \mathrm{a}^{-1}: \text { rheological }}$ water content in per cent)

$c$ : adjustable parameter in the expression of the stress

$d=1-c^{2}$ field (values in Table 3)

$s=1+c^{2}$

$U$ : mean velocity at the bottom (sliding velocity)

$y=c^{2}$ (besides a Cartesian coordinate)

$z=z_{\mu} \equiv a \cos \omega x=a \cos (2 \pi x / \lambda)$ : profile of a bed model

$\eta$ : ice viscosity

$\sigma_{x}, \sigma_{y}, \sigma_{z}, \tau_{y z}, \tau_{z x}, \tau_{x y}$ : components of stress

$\sigma_{0}$ : mean normal stress

$\sigma_{1}<\sigma_{2}<\sigma_{3}$ : principal stresses

$\tau=\left(\frac{1}{2} \tau_{i j} \tau_{i j}\right)^{\frac{1}{2}}$ : effective shear stress

$\tau_{i j}$ : deviatoric stresses

$\sigma_{\mathrm{b}}, \tau_{\mathrm{b}}$ : mean normal and shear stress at the ice-bed interface 
Non-dimensional variables

$$
\begin{aligned}
& X=\omega x, Z=c \omega z: \text { coordinates } \\
& S_{X}(X, Z)=\frac{a \omega}{\tau_{\mathrm{b}}}\left[\begin{array}{l}
\left.\sigma_{x}(x, z)-\sigma_{\mathrm{b}}\right], S_{Y}=S_{0}, S_{Z}: \text { normal } \\
\text { stresses }
\end{array}\right. \\
& \Theta(X, Z)=\frac{a \omega}{\tau_{\mathrm{b}}} \tau(x, z), \Theta_{X X}, \Theta_{X Z}: \text { deviatoric stresses }
\end{aligned}
$$

\section{INTRODUGTION}

The theories of glacier sliding and glacial erosion have been developed considering temperate ice as an impermeable and dry material. The time has come to adopt a more realistic model.

The permeability of bubble-free ("blue") temperate glacier ice is a well-documented and accepted fact (Lliboutry, 1971). Raymond and Harrison (1975) have examined the water veins at three-grain intersections just after ice cores were retrieved from depths up to $60 \mathrm{~m}$. They inferred the following percolation rates, when the pressure gradient in a vertical vein is the same as in stagnant glacier ice: $19 \mathrm{~cm} \mathrm{a}^{-1}$ in fine-grained ice (grainsize $\sim 2 \mathrm{~mm}$ ), $0.8 \mathrm{~cm} \mathrm{a}^{-1}$ in coarse-grained blue ice (grainsize $\sim 2 \mathrm{~cm}$ ) and $0.05 \mathrm{~cm} \mathrm{a}^{-1}$ in coarse-grained white ice.

Note that the percentage of blue ice increases with depth. When coring to the bottom of glacier d'Argentière, down to $107 \mathrm{~m}$, only $10-20 \%$ of blue ice was found in the cores, the remnant being white. Below $107 \mathrm{~m}$, the amount of blue ice increased and reached $90-95 \%$ between $180 \mathrm{~m}$ and the bottom at $237 \mathrm{~m}$ (Hantz and Lliboutry, 1983).

From chemical analyses, Berner and others (1977) estimated that $2-4 \mathrm{~cm}$ of water percolate per year through Griegsgletscher. At depth, it dissolves air under pressure. In this way, after several centuries, white ice might become bubble-free.

Hutter (1982) and Blatter and Hutter (1991), in their study of polythermal glaciers, considered a Fourier-type diffusion of moisture in temperate ice. Since neither the corresponding diffusivity coefficient nor the boundary conditions for water fluxes could be estimated, they decided to neglect in their numerical applications any diffusion of moisture through ice. Fowler (1984) suggested that recrystallization and flow of ice might strongly enhance the flow of water through the capillary network but he did not offer a predictive model. Therefore, Shoemaker (1990) considered the two extreme cases only: impermeability, or a permeability sufficiently large to allow perfect drainage of any internally produced meltwater.

As for wetness, temperate ice contains much more of the liquid phase than the infilling of the capillary network. The water content has been measured, from surface to bottom, in the accumulation zone of Mer de Glace (Vallon and others, 1976), and in the ablation zone of glacier d'Argentière (Montmollin and others, unpublished). It varies at random at the decimetric scale, between 0 and $2 \%$, without any correlation with the grain-size or the fabric. This important result may be found in Lliboutry and Duval (1985) or in Lliboutry (1987b, p. 122-24), where a tentative explanation is given. It is grounded on the fact that most of the water is found in water lenses at grain boundaries, of similar shape (their convexity being governed by the interfacial energies). The lenses enlarge with time, because of the viscous dissipation of heat, until they reach a vein and empty. (As we shall see, the water pressure is always less in the veins.) Therefore, the random distribution of the water content that resulted from the different salt contents of successive snowfalls is perpetuated.

Contrary to previous statements, in stressed ice the very local temperature at an ice-water interface is the melting temperature that corresponds to the hydrostatic pressure in the water, which is equal to the normal stress in the ice that acts on the interface (Lliboutry, 1964). As shown later, capillary forces (that cause unequal normal pressures against both sides of an interface) and salt content (that lowers the temperature) have negligible effects. Therefore, melting and refreezing at adjacent water inclusions should occur until lenses exist only at the grain boundaries where the normal pressure is the highest (the local temperature the lowest). Thus, with several assumptions that are discussed in the first half of this paper, we may consider that the temperature of wet glacier ice is determined by the local stress, more precisely by the minimum normal stress (when tensile stresses are taken as positive). They are not determined, as in standard theory, by the temperatures or heat fluxes at the distant boundaries of the body and by Fourier's law. Of course, there are heat fluxes governed by Fourier's law but they may be drawn directly from the stress field.

I have put forward this theory of "locally stresscontrolled temperatures" at a symposium held in 1985 at Interlaken (Lliboutry, 1986). As a stress field, I used the asymptotic solution given by Nye (1969) for the sliding on a hard bed of a Newtonian viscous body, without icebedrock separation (cavitation, in the glaciological sense). The surprising result was an extremely large freezing trend at the glacier sole and internal melting in its vicinity. In my book (Lliboutry, 1987b), I presented this theory on p. 160-64, using this time the third-power law of viscosity but always the asymptotic solution. Later, I improved the stress field by considering a bed profile with finite amplitudes. This can significantly change the results, as shown in the second half of this paper. More importantly, I realized that the water which is produced a short distance above the bed more or less equals the amount of water that the freezing trend at the glacier sole requires. My results have been given in two manuscripts, submitted in December 1989 to the Journal of Glaciology, fused into a single one in June 1990, and finally rejected in March 1991 because it was too long.

Meanwhile, one of those attending the Interlaken symposium picked up the idea of locally stress-controlled temperatures and submitted to the same journal a paper on this topic in May 1989 (Shoemaker, 1990). He did not consider the varying stress field due to sliding on a bumpy bed. He made a calculation only in the asymptotic case where deviatoric stresses in the ice would derive from shrinking due to the loss of internal meltwater. This assumption is untenable, because the overlying ice can contract and cope with this loss of volume. Moreover, the many delicate points of the theory have been overlooked. They will be successively addressed in this paper (which is not merely a shortened version of the rejected paper): 
1. When water appears continuously within the ice, can it drain off?

2. Which time-scale must be adopted in order to have a local thermodynamic equilibrium, although a temperate glacier as a whole is not in thermodynamic equilibrium?

3. Can the local stress, at the space scale of a crystal, or even of a water lens, be equated with the macroscopic stress that is considered in continuum mechanics?

4. Can we use as a model for the bed a series of smooth bumps, ignoring the minute asperities?

5. Which is the best analytical expression of the stress field over a wavy bed, with non-linear rheology and finite amplitudes?

6. How to cope with the mathematical singularities that this analytical expression yields?

7. How to choose the bed parameters in order to obtain realistic freezing trends?

It will be shown that, with locally stress-controlled temperatures, the water film that, in standard sliding theory, flows at the interface from the stoss sides of the bumps to their lee sides does not exist. Water migrates by the capillary network, within a bottom ice layer of thickness $h_{\mathrm{w}}$. Nevertheless, this change does not lead to dramatic changes in the sliding laws.

Since, as an average, ice is continuously formed at the sole of a temperate glacier, while water appears above and drains off, a permanent layer of accreted regelation ice, with mean thickness $h_{\mathrm{i}}$, exists at the sole. The values of $h_{\mathrm{w}}$ and $h_{\mathrm{i}}$ will be estimated. They are essential for any study of the salt content or isotopic composition of bottom ice. The accreted layer may appear as a thin silty layer, which is actually observed in many mountain temperate glaciers. It has to be considered in any modelling of glacial abrasion, a topic that will be dealt with in another paper.

\section{WATER PRESSURE IN LENSES AND WATER VEINS}

The microscopic scale, i.e. the scale of water inclusions and ice grains, will be considered first. To ground assertions made in the introduction, first recall some of the laws of capillarity and thermodynamics.

At an ice-water interface, the interfacial energy $\gamma$ causes the normal pressures in the ice $\left(p_{\mathrm{n}}\right)$ and in the water $\left(p_{\mathrm{w}}\right)$ to be different. Denoting $r_{1}, r_{2}$, the principal radii of curvature of the interface (both positive in the case of a water lens), we have:

$$
p_{\mathrm{w}}=p_{\mathrm{n}}+\gamma\left(1 / r_{1}+1 / r_{2}\right) \text {. }
$$

For a given $p_{\mathrm{n}}, p_{\mathrm{w}}$ is lower in veins than in lenses because of the opposite concavities of their walls. For a lens with diameter $\delta$, according to Walford (quoted by Nye and Mae (1972); $\left.r_{1}=r_{2}=\delta /\left(2 \sin 16^{\circ}\right)\right)$. With $\gamma=0.034 \mathrm{~J} \mathrm{~m}^{-2}$, for $\delta=1 \mathrm{~mm}$, it follows $p_{\mathrm{w}}=$ $p_{\mathrm{n}}+37.4 \mathrm{~Pa}$. For veins, according to Raymond and Harrison (1975), $r_{1} \sim 8.5 \times 10^{-5} \mathrm{~m}$, and $1 / r_{2}=0$, whence $p_{\mathrm{w}}=p_{\mathrm{n}}-400 \mathrm{~Pa}$. Therefore, in unstressed ice, when a lens on a grain facet becomes large enough to reach a vein at the periphery of the facet, it empties into the capillary network.

In stressed ice, the water-pressure difference between lenses and veins is still larger, because the lenses are found at grain boundaries more or less perpendicular to the maximum compressive stress. With $r_{1}, r_{2}, r_{3}$ denoting this time, the radii of curvature of the three cylindrical facets of a vein, and $p_{1}, p_{2}, p_{3}$ the corresponding values of $p_{\mathrm{n}}$ :

$$
\begin{aligned}
p_{\mathrm{w}} & =p_{1}+\frac{\gamma}{r_{1}}=p_{2}+\frac{\gamma}{r_{2}}=p_{3}+\frac{\gamma}{r_{3}} \\
& =\frac{p_{1}+p_{2}+p_{3}}{3}+\frac{\gamma}{3}\left(\frac{1}{r_{1}}+\frac{1}{r_{2}}+\frac{1}{r_{3}}\right) .
\end{aligned}
$$

Since the $p_{\mathrm{i}}$ values are unequal, the curvatures are unequal. Nevertheless, the last term remains of the same order as before, $-400 \mathrm{~Pa}$. The walls of a vein are more or less in three directions at $120^{\circ}$ from each other. Taking the $z$ axis in the direction of the vein, a simple calculation shows that in this case:

$$
\frac{p_{1}+p_{2}+p_{3}}{3}=-\frac{\sigma_{x}+\sigma_{y}}{2} .
$$

Since this value is less than the maximum compressive stress, whereas at lens walls it is equal, the water pressure in the veins is lower than in a water lens by more than $437 \mathrm{~Pa}$. In veins perpendicular to the lens, it is lower than in veins parallel to it.

The water discharge in a vein is $k_{\mathrm{v}}$, denoting a constant, $s_{\mathrm{v}}$, the cross-sectional area of the vein, and $g_{z}$, the component of gravity in the direction of the vein:

$$
q_{\mathrm{v}}=k_{\mathrm{v}} s_{\mathrm{v}}^{2}\left[\rho_{\mathrm{w}} g_{z}+\frac{\partial}{\partial z}\left(\frac{\sigma_{x}+\sigma_{y}}{2}\right)\right] \text {. }
$$

The first term is smaller than the second one by two orders of magnitude and may be neglected, as long as we deal with the vicinity of an uneven bed.

\section{TEMPERATURES AT THE MICROSCOPIC SCALE}

The Kelvin temperature $T$ in the local equilibrium state depends on $p_{\mathrm{n}}, p_{\mathrm{w}}$, and on the entropy difference between water and ice per unit mass, that is $L / T$, with $L$ denoting the latent heat of melting. It also depends on the concentration of dissolved salts in the inclusions $(\mu$, in equivalents per $\mathrm{kg})$ and of dissolved air $\left(\nu p_{\mathrm{w}}\right.$, in moles per kg). Substituting the value of Equation (1) of $p_{\mathrm{w}}$, the formula reads:

$$
T-T_{0}=-C_{\mathrm{m}} p_{\mathrm{n}}-C_{\mathrm{s}} \mu+C_{\mathrm{r}}\left(1 / r_{1}+1 / r_{2}\right)
$$

with the values of $C_{\mathrm{m}}, C_{\mathrm{s}}$ and $C_{\mathrm{r}}$ that are indicated at the beginning of this paper.

The total curvature of a vein wall is of order $-10^{4} \mathrm{~m}^{-1}$, and the one of a lens wall of order $10^{3} \mathrm{~m}^{-1}$. Thus, the last term in Equation (5) is of order $10^{-4} \mathrm{~K}$. Salt concentration in wet glacier ice is of order $10^{-4}$ equiv. $/ \mathrm{kg}$ at most (Souchez and others, 1973) and, since the water content of bottom ice is about $2 \%, \mu$ is less than $10^{-2}$. The corresponding lowering of the melting temperature is less than $0.01 \mathrm{~K}$. In deforming ice, near the glacier sole, $p_{\mathrm{n}}$ may differ from one wall to another, according to its orientation, by up to $1 \mathrm{MPa}$, providing temperature 
differences up to $0.1 \mathrm{~K}$. In bottom ice, the temperature is lowered a little because of the salt content, but its variations depend almost exclusively on the variations of $p_{\mathrm{n}}$. For modelling heat transfers in deforming ice, only the stress-dependence of temperature has to be considered.

The assumption that ice is deforming, i.e. that the deviatoric stresses are conspicuous, is important. The author had the opportunity to examine stagnant temperate ice at the bottom of Mer de Glace, thanks to a tunnel dug at the tip of its tongue by the hydro-electric agency EDF, in the 1970s. (This tip disappeared in the succeeding years, impeding more detailed and quantitative observations.) The cross-section of the bed there had a V-shape, with large boulders in the furrow, amongst which ran the subglacial stream. All the ice around the tunnel was blue, excepting ribbons of white ice with very large air bubbles that rose from the ceiling, parallel to the almost vertical rockwall on one side. Near the boulders, crystals were unusually large $(5-10 \mathrm{~cm})$ and some water pockets $\left(\sim 10 \mathrm{~cm}^{3}\right)$ were observed. Clearly, this ice had suffered post-kinematic recrystallization over a long time, with the interfacial energies as the main driving factor.

For the general case, the mean crystal area on thin slices of bottom (blue) ice is $0.4-1.3 \mathrm{~cm}^{2}$ (Montmollin and others, unpublished). To assume local thermo-dynamic equilibrium, at the centimetric scale of a grain, means that temperature and stress are uniform within a grain. Then, $\sigma_{1}<\sigma_{2}<\sigma_{3}$, denoting the three principal stresses (compressive, and thus negative):

(a) Water lenses are more or less perpendicular to $\sigma_{1}$;

(b) The local Celsius temperature is:

$$
T=-C_{\mathrm{m}} \sigma_{1} .
$$

When flow over an uneven bed causes the stress to change, the temperature must follow the change in $\sigma_{1}$. It may happen that the stress change causes lenses to disappear and others with a different orientation to appear. On the other hand, the heat flux caused by $\nabla T$ (at the macroscopic scale) may supply heat or cold to the crystal. There is also some viscous dissipation of heat (it will be found to be negligible in front of the former heat transfer). All these causes induce melting or refreezing at the lens walls, hence very local volume changes and the corresponding stresses.

Ice diffusivity is large enough $\left(1.16 \mathrm{~mm}^{2} \mathrm{~s}^{-1}\right)$ to ensure that a steady temperature field within the crystal is reached in a few minutes. Then, the temperature gradients between melting lenses and freezing ones is several hundredths of a degree over several millimetres. The corresponding heat fluxes are of order $10 \mathrm{~J} \mathrm{~m}^{-2} \mathrm{~s}^{-1}$. They correspond to melting or freezing at the lens walls at rates of order $0.1 \mathrm{~mm} \mathrm{~h}^{-1}$. It should take some hours for a new set of lenses to be formed. Since the temperate ice viscosity, in transient creep, is less than $10^{7} \mathrm{~Pa} \mathrm{~s}$, and the elastic shear modulus of ice is $3.45 \times 10^{9} \mathrm{~Pa}$, the time constant of stress relaxation is of order $10^{-2} \mathrm{~s}$ at most and very local stresses due to volume changes remain negligible.

The slowest governing factor for local temperatures is the slow change of the macroscopic stress field. Large stress changes may demand several hours before the local thermodynamic equilibrium is restored. Note that, in laboratory experiments with non-recrystallizing stressed ice, Nye and Mae (1972) found about $1 \mathrm{~h}$.

Such large stress changes occur when bottom ice slides and flows from the stoss side to the lee side of a bump. Even with fast sliding, e.g. $2 \mathrm{~cm} \mathrm{~h}^{-1}$, local thermal equilibrium is always reached, unless the wavelength is centimetric or smaller. For this reason, and because of the grain-size, Equation (6) is not valid when dealing with minute bumps. For minute asperities, the classical sliding theory must be used instead.

\section{MICROSCOPIC STRESSES AND MACROSCOPIC STRESS}

At the grain scale, strain rates and stresses in deforming glacier ice are not uniform, because individual crystals are strongly anisotropic. The standard homogenization procedure, which has been developed to deal with the plastic deformation of cubic metallic crystals, assumes that the microscopic strain rate is uniform and equals the macroscopic one, whereas microscopic and macroscopic stresses differ. (With this assumption, equilibrium conditions for stress are not obeyed.) For creeping ice, the opposite assumption, the same stress but different strains in adjacent grains, should be much closer to the truth, for the following reasons (Lliboutry, 1987b, p. 455-57):

1. In deforming temperate glacier ice, a multi-maxima fabric is always found. With this fabric, grains are never in an unfavourable orientation for shear by gliding on basal planes. Also, they are not in the most favourable one.

2. Given the third-power viscous law, a small local perturbation of stress can ensure a large perturbation of the strain rate.

3. Compatibility of strains in two adjacent crystals is readily obtained in two ways: (a) thanks to grainboundary migration, as shown by Means and Jessel (1986), and more intuitively explained in my quoted book. Coincidence-site lattices (Higashi, 1978), that stabilize the multi-maxima fabric, also make boundary migration easy. (b) Thanks to micro-slip on the grain boundaries, or something similar, linked with the modification of bundles of dislocations that are gathered at these boundaries. This process should account for most of the recoverable transient creep on unloading (Lliboutry, 1987b, p. 428-31).

The reason why polycrystalline ice is much more viscous than single isolated crystals is because of piling up of dislocations at grain boundaries. In single crystals they escape freely at the surface. It is not, as often asserted, due to the existence of misoriented hard grains with very high local stresses that would govern the macroscopic strain rate.

Therefore, in Equation (4) giving the water flux within the ice, and in Equation (6) relating the temperature to the principal stress $\sigma_{1}$, macroscopic stresses may be used. The only requirement is that the macroscopic stress field is almost uniform at the space scale of a grain. Again, we cannot use these formulas to 
deal with sliding on very small obstacles. In the following, sliding on a sine curve will be tackled. Its wavelength $\lambda$ must be large in front of the centimetric size of the grains. (As an application, $\lambda=0.24 \mathrm{~m}$ will be used.)

\section{ICE ACGRETION AND INTERNAL MELTING ASSUMING NYE'S STRESS FIELD}

Consider a hard bed whose micro-relief is independent of the transverse coordinate $y$, and whose longitudinal profile is the sine curve:

$$
z=z_{\mu}(x) \equiv a \cos \omega x .
$$

The stress field is assumed to be periodic in $x$. At the scale of the micro-relief, the bed is assumed to be perfectly smooth (no shear stress against it). Which values of $a$ and $\omega$ allow the best modelling of a real bed will be considered later. At a large scale (not large enough to require gravity to be considered in the stress equations), the average value of $\sigma_{z}$ is $\sigma_{\mathrm{b}}$, and the average value of $\tau_{x z}$ is $\tau_{\mathrm{b}}$. For given ice properties, when there is no ice-bed separation, the average forward velocity (the sliding velocity), say $U$, is then determined.

Further simplifications are to assume ice to be Newtonian viscous and to consider the asymptotic case $a \omega \ll 1$. This approximation is so crude that no adjustment to field data will be attempted, but it will allow the introduction of the main new concepts. Ignoring phase changes, the asymptotic solution for this plane problem in continuum mechanics, given independently by Nye (1969) and Kamb (1970), is:

$$
\begin{aligned}
& \sigma_{x}=\sigma_{\mathrm{b}}+\frac{2 \tau_{\mathrm{b}}}{a \omega}(1-\omega z) \mathrm{e}^{-\omega z} \sin \omega x \\
& \sigma_{y}=\sigma_{0}=\frac{\sigma_{x}+\sigma_{z}}{2}=\sigma_{\mathrm{b}}+\frac{2 \tau_{\mathrm{b}}}{a \omega} \mathrm{e}^{-\omega z} \sin \omega x \\
& \sigma_{z}=\sigma_{\mathrm{b}}+\frac{2 \tau_{\mathrm{b}}}{a \omega}(1+\omega z) \mathrm{e}^{-\omega z} \sin \omega z \\
& \tau_{x z}=-\frac{2 \tau_{\mathrm{b}}}{a \omega} \omega z \mathrm{e}^{-\omega z} \cos \omega x \\
& \tau_{y z}=\tau_{x y}=0 .
\end{aligned}
$$

The effective shear stress is :

$$
\tau=\left[\left(\frac{\sigma_{x}-\sigma_{z}}{2}\right)^{2}+\tau_{x z}^{2}\right]^{\frac{1}{2}}=\frac{2 \tau_{\mathrm{b}}}{a \omega} \omega z \mathrm{e}^{-\omega z} .
$$

The principal stresses are $\sigma_{1}=\sigma_{0}-\tau, \sigma_{2}=\sigma_{0}, \sigma_{3}=$ $\sigma_{0}+\tau$. Thus, with the new theory, the temperature field is (in Celsius):

$$
T=C_{\mathrm{m}}\left(\sigma_{0}-\tau\right)=C_{\mathrm{m}}\left[\sigma_{\mathrm{b}}+\frac{2 \tau_{\mathrm{b}}}{a \omega}(\sin \omega x-\omega z) \mathrm{e}^{-\omega z}\right] .
$$

The vertical heat flux follows:

$$
\phi_{z}=-K_{\mathrm{i}} \frac{\partial T}{\partial z}=K_{\mathrm{i}} C_{\mathrm{m}} \frac{2 \tau_{\mathrm{b}}}{a}(1-\omega z+\sin \omega x) \mathrm{e}^{-\omega z} .
$$

In particular, the heat flux entering the ice at the icebed interface $(z=0)$, say $\phi_{\mathrm{i}}$, is never negative, as is $(1+\sin \omega x)$.

Geothermal heat reaches the interface. There is also a heat flux through the bedrock due to the oscillations of $T$ at the interface, and governed by $\nabla^{2} T=0$ in the bedrock; its average is zero. The mean ice-accretion rate at the interface is thus $(\langle\rangle$ denoting an average for all values of $x$ ):

$$
\langle r\rangle=\frac{\left\langle\phi_{\mathrm{i}}\right\rangle-\phi_{\mathrm{g}}}{\rho L}=\frac{2 A \tau_{\mathrm{b}}}{a}-\frac{\phi_{\mathrm{g}}}{\rho L} .
$$

$A$ is the "melting-refreezing parameter" that is defined at the beginning of the paper. Since $A=21.4 \mathrm{~cm}^{2} \mathrm{a}^{-1} \mathrm{bar}^{-1}$, $\tau_{\mathrm{b}} \sim 1$ bar and $\phi_{\mathrm{g}} /(\rho L) \sim 1 \mathrm{~cm} \mathrm{a}^{-1}$, there is a trend in ice accretion when $a<40 \mathrm{~cm}$. Of course, enough water must be available for that; otherwise ice would become cold and the theory would not hold.

Within the ice, the volume rate of ice melting per unit volume is:

$$
\begin{aligned}
m=\frac{K_{\mathrm{i}}}{\rho L} \nabla^{2} T & =A \nabla^{2}\left(\sigma_{0}-\tau\right) \\
& =A \frac{2 \tau_{\mathrm{b}} \omega}{a}(2-\omega z) \mathrm{e}^{-\omega z} .
\end{aligned}
$$

It is independent of $x$ because, for a Newtonian viscous body, $\nabla^{2} \sigma_{0}=0$, and in the considered case $\tau$ is $x$ independent. Above $z=2 / \omega, m$ becomes negative, indicating a freezing rate; a small one because of the exponential factor. The total melting rate in a vertical column of cross-section unity, up to level $z$, is

$$
\int_{0}^{z} m \mathrm{~d} z=A \frac{2 \tau_{\mathrm{b}}}{a}\left[1-(1-\omega z) \mathrm{e}^{-\omega z}\right] .
$$

Ice rises above the bed with the vertical velocity given by Equation (12), but it melts continuously. Since the water content cannot be larger than about $2 \%$, the meltwater is continuously expelled. Therefore, the vertical ice velocity is:

$$
\langle r\rangle-\int_{0}^{z} m \mathrm{~d} z=A \frac{2 \tau_{\mathrm{b}}}{a}(1-\omega z) e^{-\omega z}-\frac{\phi_{\mathrm{g}}}{\rho L} .
$$

In the general case, this velocity is positive for $z=0$ and it changes sign at some value $h_{\mathrm{i}}$ of $z$ that is less than $1 / \omega$. Thus, a permanent layer of regelation ice is found at the bottom of the glacier. Above $h_{\mathrm{i}}$, small rock debris embedded in the glacier moves down with the ice, but it cannot reach the bed. (Only large debris fragments may touch the bed and scratch it.)

\section{WATER FLUXES ASSUMING NYE'S STRESS FIELD}

From Equation (14), the total water produced within the ice per unit time and unit area is equivalent to a volume of ice $2 A \tau_{b} / a$. It is larger than the one ice accretion demands by $\phi_{\mathrm{g}} / L$, if the flow in the water veins is in the right direction. This point will now be examined.

According to Equation (4), the water fluxes in the $x$ and $z$-directions are:

$$
\begin{aligned}
& q_{x}=k \frac{\partial}{\partial x}\left(\frac{\sigma_{y}+\sigma_{z}}{2}\right)=k \frac{\tau_{\mathrm{b}}}{a}(\omega z+2) \mathrm{e}^{-\omega z} \cos \omega x \\
& q_{z}=k \frac{\partial}{\partial z}\left(\frac{\sigma_{x}+\sigma_{y}}{2}\right)=k \frac{\tau_{\mathrm{b}}}{a}(\omega z-3) \mathrm{e}^{-\omega z} \sin \omega x
\end{aligned}
$$


where $k$ is a positive permeability coefficient that depends on the grain-size and on the cross-sectional area of the veins. The latter may vary, hence $k$. Any vertical water flux is possible but its direction is determined by the stress field. Since $q_{z}=0$ at $z=3 / \omega=h_{\mathrm{w}}$, no water flux crosses this level.

In the layer $0<z<h_{\mathrm{w}}$, water flows up over stoss sides $(\sin \omega x<0)$. Part of it allows the freezing that occurs in the layer $2 / \omega<z<3 / \omega$. Water flows down over the lee sides $(\sin \omega x>0$ ), draining off meltwater that appears below $z<2 / \omega$. As a balance, the outflow would allow (without geothermal flux) a mean accretion rate:

$$
\int_{0}^{3 / \omega} m \mathrm{~d} z=A \frac{2 \tau_{\mathrm{b}}}{a}\left(1+2 \mathrm{e}^{-3}\right) .
$$

It is larger than required by $4 \mathrm{e}^{-3} A \tau_{\mathrm{b}} / a=0.2 A \tau_{\mathrm{b}} / a$.

Over $z=h_{\mathrm{w}}$, slight freezing occurs at the expense of the surface water. The global balance of water fluxes is the same as if some surface water crossed the barrier at $z=h_{\mathrm{w}}$ and reached the bed, at a rate $0.2 A \tau_{\mathrm{b}} / a$.

\section{BEST ANALYTICAL EXPRESSION OF THE STRESS FIELD OVER A SINE PROFILE HAVING ANY AMPLITUDE, WITH NON-LINEAR RHE- OLOGY}

To begin with, phase changes will be ignored.

With a realistic rheology, namely third-power law isotropic viscosity, the velocity and stress fields over a sine profile cannot be expressed with known functions, even in the asymptotic case $a \omega \rightarrow 0$. Nevertheless, approximate analytical expressions of both fields, including adjustable parameters, may be written. (They are called "trial functions".) Next, the two complementary variational theorems allow calculation of the best value of the adjustable parameters. The method leads to an upper and a lower bound for $\tau_{\mathrm{b}}^{3} / U$, very close to each other when the trial functions have been cleverly chosen. The method has been described in Lliboutry (1987b, p. 35659). In the asymptotic case, the result is:

$$
(1.435)^{3} \leq \frac{B}{U a \omega^{2}}\left(\frac{\tau_{\mathrm{b}}}{a \omega}\right)^{3} \leq(1.485)^{3} .
$$

The accuracy of $\tau_{\mathrm{b}}^{3} / U$ does not guarantee that the trial fields, with adjusted parameters, are accurate. Therefore, Meysonnier (1983) computed the solution by the finiteelement method for different non-zero values of $a \omega$. He found that the analytical fields are accurate provided that the overall shear stress $\tau_{\mathrm{b}}$ is taken into account, as did Kamb (1970). Meysonnier parameterized his results as the following law:

$$
U a \omega^{2}=B\left(\frac{\tau_{\mathrm{b}}}{1.46 a \omega}\right)^{3}\left[1+7.5(a \omega)^{2}\right] .
$$

Therefore, my trial stress field, with the abovementioned correction, is the best analytical expression that is available to date, and will be used henceforth. Whether Equation (19) has to be modified to take phase changes into account will be examined later. This stress field is drawn from the Airy stress function:

$$
\chi=-\frac{2 \tau_{\mathrm{b}}}{a \omega^{3}}(1+c \omega z) \mathrm{e}^{-\alpha \omega z} \sin \omega x-\tau_{\mathrm{b}} x z
$$

where $c$ is a numerical coefficient that decreases slowly from 0.81447 when $a w$ increases from zero. It is calculated and given in Appendix I.

The components of stress are:

$$
\sigma_{x}=\sigma_{\mathrm{b}}+\frac{\partial^{2} \chi}{\partial z^{2}}, \quad \sigma_{z}=\sigma_{\mathrm{b}}+\frac{\partial^{2} \chi}{\partial x^{2}}, \quad \tau_{x z}=-\frac{\partial^{2} \chi}{\partial x \partial z} .
$$

To simplify their expressions, the following notations and reduced variables will be used.

$$
\begin{aligned}
& c^{2}=y, \quad 1+y=s, \quad 1-y=d, \\
& c a \omega=\alpha, \quad \omega x=X, \quad c \omega z=Z, \\
& \sigma_{j}-\sigma_{\mathrm{b}}=\frac{\tau_{b}}{a \omega} S_{\mathrm{J}}, \quad(j=0, x, z), \quad \tau_{x z}=\frac{\tau_{\mathrm{b}}}{a \omega} \Theta_{X Z} .
\end{aligned}
$$

It is found:

$$
\begin{aligned}
S_{X}= & 2 y(1-Z) \mathrm{e}^{-Z} \sin X \\
S_{Y}= & S_{0}=\frac{S_{X}+S_{Z}}{2}=(s+d Z) \mathrm{e}^{-Z} \sin X \\
S_{Z}= & 2(1+Z) \mathrm{e}^{-Z} \sin X \\
\Theta_{X Z}= & a \omega-2 c Z \mathrm{e}^{-Z} \cos X \\
\Theta_{X X}= & -\Theta_{Z Z}=\frac{S_{X}-S_{Z}}{2}=-(d+s Z) \mathrm{e}^{-Z} \sin X \\
\Theta^{2}= & \Theta_{X X}^{2}+\Theta_{X Z}^{2} \\
= & 4 y Z^{2} \mathrm{e}^{-2 Z}+d\left(d+2 s Z+d Z^{2}\right) \mathrm{e}^{-2 Z} \sin ^{2} X \\
& \quad-4 \alpha Z \mathrm{e}^{-Z} \cos X+(a \omega)^{2} .
\end{aligned}
$$

Note that the shear stress on the bed, at the scale of the micro-relief, is not $\tau_{b}$. Subscripts $\mu$ referring to the exact values on the sine profile, it is:

$$
\tau_{\mathrm{b} \mu}=\left.\tau_{x z}\right|_{z=z_{\mu}} \cos 2 \beta-\left.\tau_{x x}\right|_{z=z_{\mu}} \sin 2 \beta
$$

with $\tan \beta=-a \omega \sin X$. The leading term is found to be:

$$
\tau_{\mathrm{b} \mu}=\tau_{\mathrm{b}}\left(1-2 c^{2}\right) \cos 2 X
$$

which is a good approximation, without trend, of the boundary condition $\tau_{b \mu}=0$.

The trouble with this improved stress field is that $\Theta$ has singularities at the points of the $(X-Z-a \omega)$ space where it vanishes. It happens when $\Theta_{X X}$ and $\Theta_{X Z}$ are both zero. These points are sought in Appendix II. In the vicinity of these points, $\Theta_{X X}=b\left(X-X_{0}\right), \Theta_{X Z}=$ $e\left(X-X_{0}\right)$, and thus $\Theta=\sqrt{b^{2}+e^{2}}\left|X-X_{0}\right|$. Thus, $\partial \Theta / \partial X$ jumps from a negative to a positive value when $X$ crosses the value $X=X_{0}$. In the vicinity of a singularity $|\nabla \Theta|$ becomes extremely large. These spikes must be smoothed out, because they have no physical meaning. A mathematical derivative is defined by giving to the variables $x$ or $z$ infinitesimal increments, and increments smaller than the grain-size cannot be considered.

\section{WATER PRODUCTION AND WATER FLUXES}

The Celsius temperature within the ice is:

$$
T=C_{\mathrm{m}} \sigma_{\mathrm{b}}+C_{\mathrm{m}} \frac{\tau_{\mathrm{b}}}{a \omega}\left(S_{0}-\Theta\right) \text {. }
$$




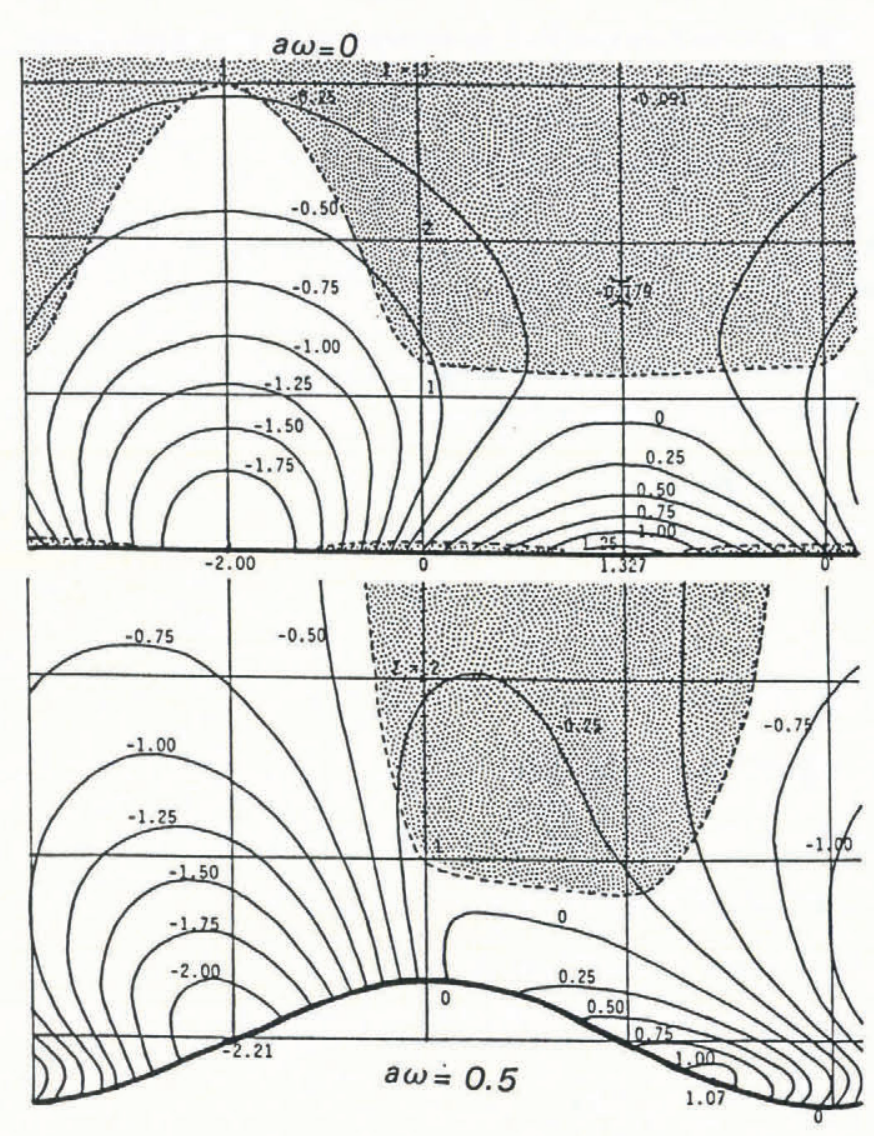

Fig. 1. Reduced temperature field in the ice, when it is locally stress-controlled, $\left(S_{0}-\Theta\right)$. The Celsius temperature is $T=C_{\mathrm{m}} \sigma_{\mathrm{b}}+\left(C_{\mathrm{m}} \tau_{\mathrm{b}} / a \omega\right)\left(S_{0}-\Theta\right)$. The areas where there is freezing instead of melting are shaded. The barrier for capillary flow, at $Z=Z_{\mathrm{w}}$, is above the drawn area.

Contour lines of the reduced temperature field $\left(S_{0}-\theta\right)$ are displayed in Figure 1, in the asymptotic case $a \omega=0$, and when $a \omega=0.5$. Since $\Theta$ is always positive, the area in the $X-Z$ plane on the lee side of the bump where $T-C_{\mathrm{m}} \sigma_{\mathrm{b}}$ is positive is smaller than the area on the stoss side where it is negative, and it has steeper gradients. Therefore, more heat comes from the interface on the lee side than goes to the stoss side. For finite amplitudes, the contour lines become skew, and $X= \pm 90^{\circ}$ are no longer axes of symmetry. is:

The melting rate of ice per unit volume within the ice

$$
\frac{K_{\mathrm{i}}}{\rho L} \nabla^{2} T=A \frac{\tau_{\mathrm{b}} \omega}{a}\left[\frac{\partial^{2}}{\partial X^{2}}\left(S_{0}-\Theta\right)+y \frac{\partial^{2}}{\partial Z^{2}}\left(S_{0}-\Theta\right)\right] .
$$

The result is given in Appendix III. The area where it is negative (i.e. where freezing occurs) is shaded in Figure 1. Since $\nabla T$ vanishes at infinity upwards, the global balance of ice melting within the ice is ( $\mathbf{n}$ denoting the unit normal to the bed, pointing upwards):

$$
\begin{aligned}
r_{\mathrm{i}} & =-\frac{K_{\mathrm{i}}}{\rho L} \nabla T \cdot \mathbf{n} \\
& =-\frac{K_{\mathrm{i}}}{\rho L}\left[\frac{\partial T}{\partial z} \cos \beta-\frac{\partial T}{\partial x} \sin \beta\right]=A \frac{\tau_{\mathrm{b}}}{a} R_{\mathrm{i}}
\end{aligned}
$$

$$
\begin{aligned}
& R_{\mathrm{i}}=-\left(1+a^{2} \omega^{2} \sin ^{2} X\right)^{-\frac{1}{2}} \\
& \cdot\left[\left.c \frac{\partial\left(S_{0}-\Theta\right)}{\partial Z}\right|_{\mu}+\left.a \omega \sin X \frac{\partial\left(S_{0}-\Theta\right)}{\partial X}\right|_{\mu}\right] .
\end{aligned}
$$

The analytical expression of $R_{\mathrm{i}}$ is given in Appendix III.

The components of the water flux within the ice are found to be:

$$
\begin{aligned}
q_{x} & =k \frac{\partial}{\partial x}\left(\frac{\sigma_{y}+\sigma_{z}}{2}\right)=k \frac{\tau_{\mathrm{b}}}{a} \frac{\partial}{\partial X}\left(\frac{S_{Y}+S_{Z}}{2}\right) \\
& =k \frac{\tau_{\mathrm{b}}}{a}\left[\left(\frac{3+y}{2}\right)+\left(\frac{3-y}{2}\right) Z\right] \mathrm{e}^{-Z} \cos X \\
q_{z} & =k \frac{\partial}{\partial z}\left(\frac{\sigma_{x}+\sigma_{y}}{2}\right)=k \frac{\tau_{\mathrm{b}}}{a} c \frac{\partial}{\partial Z}\left(\frac{S_{X}+S_{Y}}{2}\right) \\
& =k \frac{\tau_{\mathrm{b}}}{a} c\left[-3 y+\left(\frac{3 y-1}{2}\right) Z\right] \mathrm{e}^{-Z} \sin X .
\end{aligned}
$$

(As a check, for Newtonian viscous ice, $y=1$, and Equations (14) are found.) The water motion in the ice is similar to the one described when ice was assumed to be Newtonian viscous. Nevertheless, the level $z=h_{\mathrm{w}}$ that water does not cross is higher. It is:

$$
Z_{\mathrm{w}}=c \omega h_{\mathrm{w}}=\frac{6 y}{3 y-1} \text {. }
$$

For $a=0, h_{\mathrm{w}}=4.936 / \omega$, and for $a \omega=0.5, h_{\mathrm{w}}=$ $9.000 / \omega$, when for Newtonian viscosity and $a \omega=0$ it was $h_{\mathrm{w}}=3 / \omega$.

\section{ICE-ACGRETION RATE}

The ice-accretion rate (melting rate when negative) reads:

$$
r=A \frac{\tau_{\mathrm{b}}}{a}\left(R_{i}+\frac{K_{\mathrm{b}}}{K_{\mathrm{i}}} R_{\mathrm{b}}\right)-\frac{\phi_{\mathrm{g}}}{\rho L} .
$$

The term in $R_{\mathrm{b}}$ corresponds to the heat fluxes in the bedrock, caused by the non-uniform temperature at the ice-bed interface. The ratio of the thermal conductivities in the bedrock and in the ice, $K_{\mathrm{b}} / K_{\mathrm{i}}$, is introduced because $A$ has been defined with $K_{\mathrm{i}}$, whereas the heat fluxes in the bed are proportional to $K_{\mathrm{b}}$.

$R_{\mathrm{i}}$, as given by Equation (28), has been computed for 24 values of $X, 15^{\circ}$ apart from each other, and for several values of $a \omega$. Some spikes appear near the zeros of $\Theta$. As stated in Appendix II, when $Z=Z_{u}$, the zeros of $\Theta$ are:

(1) For $a \omega=0$, at $X=0$ and $180^{\circ}, Z=Z_{\mu}=0$.

(2) For $a \omega=0.2525$, at $X=0$ and $Z=Z_{\mu}=0.197$.

(3) For $a \omega=0.968$, at $X= \pm 155.2^{\circ}$ and $Z=Z_{\mu}=$ -0.437 .

As previously explained, these spikes without physical meaning must be smoothed out. The smoothing may be done in several ways. This arbitrary choice introduces a significant inaccuracy in the mean value of $R_{\mathrm{i}}$ only when this mean is very small. The figures given in Table 1 correspond to the following rule: "when $\Theta_{\mu}<$ $\left(\max \Theta_{\mu}\right) / 8$, and $R_{\mathrm{i}}\left(X-15^{\circ}\right), R_{\mathrm{i}}(X), R_{\mathrm{i}}\left(X+15^{\circ}\right)$ are 
not ordered, then $R_{\mathrm{i}}(X)$ is replaced by the arithmetic mean of the three values".

The temperature at the interface reads:

$$
T_{\mu}=C_{\mathrm{m}} \sigma_{\mathrm{b}}+C_{\mathrm{m}} \frac{\tau_{\mathrm{b}}}{a \omega}\left(S_{0 \mu}-\Theta_{\mu}\right)
$$

Temperatures in the bedrock have been approximated by a truncated series that obeys $\nabla^{2} T=0$ and tends towards $-\phi_{g} z / K_{b}$ when $z \rightarrow-\infty$ :

$$
\begin{aligned}
T=- & \frac{\phi_{\mathrm{g}} z}{K_{\mathrm{b}}}+C_{\mathrm{m}} \sigma_{\mathrm{b}}+C_{\mathrm{m}} \frac{\tau_{\mathrm{b}}}{a \omega}\left[b_{0}+b_{1} \mathrm{e}^{\omega z} \sin \omega x\right. \\
& \left.+b_{2} \mathrm{e}^{\omega z} \cos \omega x+b_{3} \mathrm{e}^{2 \omega z} \sin 2 \omega x+b_{4} \mathrm{e}^{2 \omega z} \cos 2 \omega x\right] .
\end{aligned}
$$

The $b_{i}$ s have been calculated by fitting this expression

Table 1. Dimensionless accretion rate at the interface, ignoring geothermal heat and assuming $K_{\mathrm{b}}=K_{\mathrm{i}}$. It may be written $R_{\mathrm{i}}+R_{\mathrm{b}}=R_{0}+R_{1} \sin X+\cdots$

$$
\text { aw }\left\langle R_{\mathrm{i}}\right\rangle \quad\left\langle R_{\mathrm{b}}\right\rangle R_{0}=\left\langle R_{\mathrm{i}}+R_{\mathrm{b}}\right\rangle \quad \begin{gathered}
R_{1}= \\
2\left\langle\left(R_{\mathrm{i}}+R_{\mathrm{b}}\right) \sin X\right\rangle
\end{gathered}
$$

$\begin{array}{lrrrl}0 & 0.6879 & 0 & 0.6879 & 2.744 \\ 0.1 & 0.5954 & -0.0075 & 0.5879 & 2.707 \\ 0.3 & 0.2643 & 0.0045 & 0.2688 & 2.463 \\ 0.5 & 0.0835 & 0.0135 & 0.0970 & 2.093 \\ 0.7 & 0.0197 & 0.0227 & 0.0424 & 1.783\end{array}$

to 24 values of $T_{\mu}$, corresponding to steps in $X$ of $15^{\circ}$, by a least-squares procedure. The method and the results are given in Appendix IV. Next, the reduced value $R_{\mathrm{b}}$ of the heat flux entering the bedrock from the interface is easy to calculate. With the notations:

$$
\begin{aligned}
t & =a \omega \sin X, & \Phi & =\frac{\phi_{\mathrm{g}}}{K_{\mathrm{b}} C_{\mathrm{m}} \tau_{\mathrm{b}} \omega}, \\
f_{1} & =\mathrm{e}^{\omega z_{\mu}} \sin X, & f_{2} & =\mathrm{e}^{\omega z_{\mu}} \cos X, \\
f_{3} & =\mathrm{e}^{2 \omega z_{\mu}} \sin 2 X, & f_{4} & =\mathrm{e}^{2 \omega z_{\mu}} \cos 2 X,
\end{aligned}
$$

it is found:

$$
\begin{gathered}
S_{0 \mu}-\Theta_{\mu}+\Phi \frac{a \omega}{c} Z_{\mu}=b_{0}+b_{1} f_{1}+b_{2} f_{2}+b_{3} f_{3}+b_{4} f_{4} \\
R_{\mathrm{b}}=\frac{1}{\sqrt{1+t^{2}}}\left[b_{1}\left(f_{1}+t f_{2}\right)+b_{2}\left(f_{2}-t f_{1}\right)\right. \\
\left.\quad+2 b_{3}\left(f_{3}+t f_{4}\right)+2 b_{4}\left(f_{4}-t f_{3}\right)\right] .
\end{gathered}
$$

In the asymptotic case $a \omega=0, R_{\mathrm{i}}$ and $R_{\mathrm{b}}$ can be rigorously calculated. Then:

$$
\begin{array}{rlr}
S_{0 \mu} & =s \sin X, \quad \Theta_{\mu}=d|\sin X| \\
S_{0 \mu}-\Theta_{\mu} & =2 \sin X \quad & \text { when } \sin X<0 \\
& =2 y \sin X \quad \text { when } \sin X>0 \\
R_{\mathrm{i}} & =\frac{1}{c}\left[2 y^{2} \sin X+\frac{2 d y^{2}}{\Theta_{\mu}} \sin ^{2} X\right] \\
& =2 c^{3}(\sin X+|\sin X|) .
\end{array}
$$

The mean value of $R_{\mathrm{i}}$ is $\left\langle R_{\mathrm{i}}\right\rangle=4 c^{3} / \pi$. Since

$$
|\sin X|=\frac{2}{\pi}-\sum_{n=1}^{\infty} \frac{4}{4 n^{2}-1} \cos 2 n X,
$$

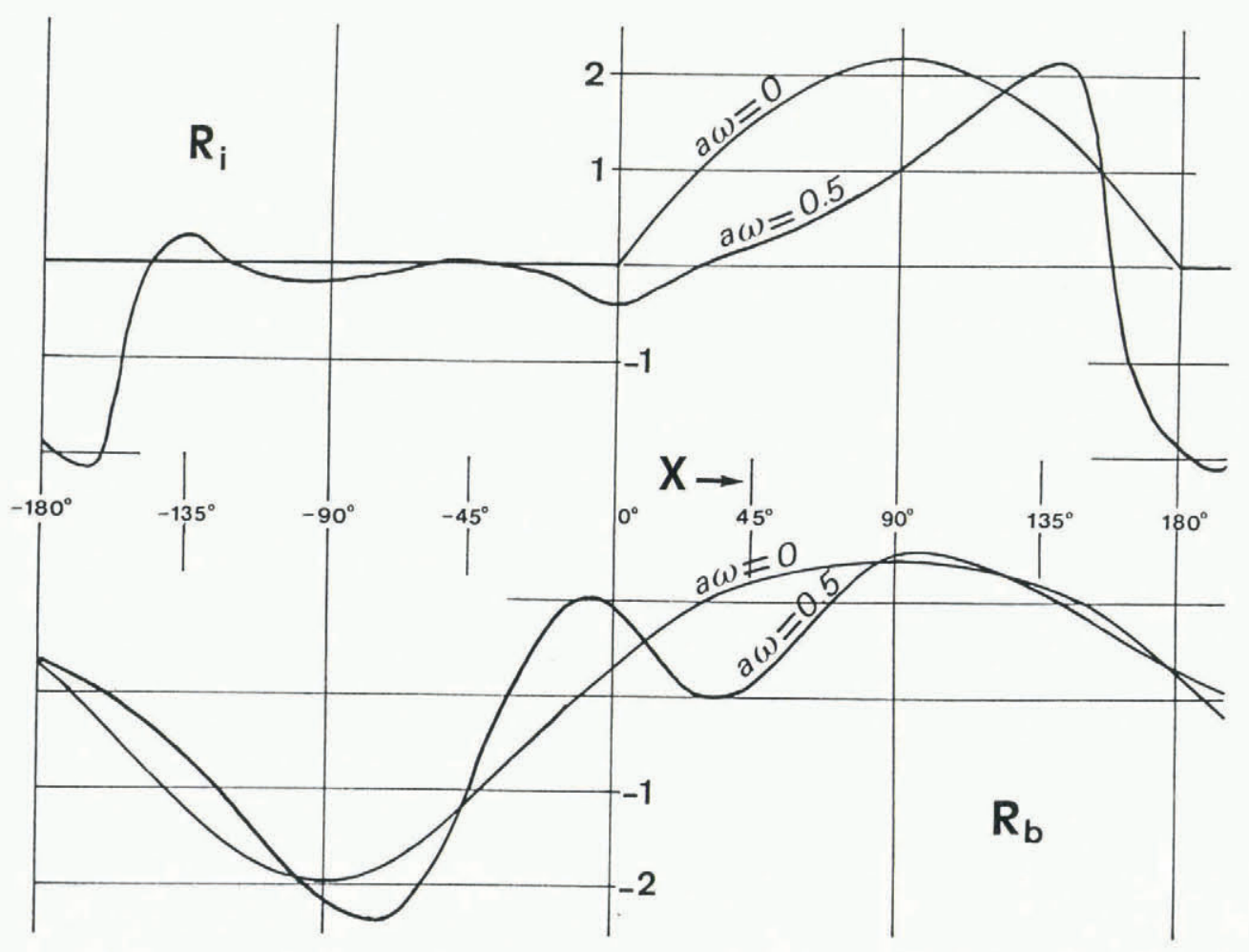

Fig. 2. Components of the reduced freezing rate at the interface (melting when negative). $R_{\mathrm{i}}$ is due to the cold coming from the ice (ignoring the viscous dissipation of heat, which is negligible). $R_{\mathrm{b}}$ is due to the cold coming from the bed, ignoring the geothermal flux. 
the temperature field in the bedrock is exactly given by an infinite Fourier series. It yields:

$$
R_{\mathrm{b}}=s \sin X+\frac{8 d}{\pi} \sum_{n=1}^{\infty} \frac{n}{4 n^{2}-1} \cos 2 n X .
$$

This series does not converge when $\sin X=0$, but this singularity must be smoothed out, as explained before.

Values of $R_{\mathrm{i}}$ and $R_{\mathrm{b}}$ at different abscissae are displayed in Figure 2. In the asymptotic case $a \omega=$ $0, R_{\mathrm{i}}$ is never negative. When finite amplitudes are considered, negative values appear in the hollows of the micro-relief, with a minimum at about $X=-167^{\circ}$, almost opposite to the maximum at about $X=138^{\circ}$. This unexpected large oscillation is not a mathematical artifact due to the vicnity of a singularity, because in this case a similar oscillation would be found near $0^{\circ}$.

As for $R_{\mathrm{b}}$, in the asymptotic case it is negative over a smaller extent than in the standard theory. With finite micro-relief amplitudes, an oscillation appears at the crests of the bumps, with a maximum at about $X=0^{\circ}$, and a minimum at $30^{\circ}$.

Mean values of $R_{\mathrm{i}}, R_{\mathrm{b}}$ and of their sum are given in Table 1. $\left\langle R_{\mathrm{b}}\right\rangle$ is always very small but $\left\langle R_{\mathrm{i}}\right\rangle$, hence $\left\langle R_{\mathrm{i}}+R_{\mathrm{b}}\right\rangle=R_{0}$, diminishes strongly for increasing values of aw. A rough parameterization is:

$$
R_{0} \approx 10^{-2 a \omega} \text {. }
$$

The fact that $\left\langle r_{\mathrm{b}}\right\rangle$ is not zero modifies Equation (12). Let us state it again. The mean thickness of the regelation layer is given by the following balance between accretion rates and internal melting, averaged for all $X$ :

$$
\begin{gathered}
\langle r\rangle=\left\langle\int_{z_{\mu}}^{h_{\mathrm{i}}} \frac{K_{\mathrm{i}}}{\rho L} \nabla^{2} T \mathrm{~d} z\right\rangle \\
\left\langle r_{\mathrm{i}}\right\rangle+\left\langle r_{\mathrm{b}}\right\rangle-\frac{\phi_{\mathrm{g}}}{\rho L}=\frac{K_{\mathrm{i}}}{\rho L}\left\langle\left.\frac{\partial T}{\partial z}\right|_{z=h_{\mathrm{i}}}\right\rangle-\frac{K_{\mathrm{i}}}{\rho L}\left\langle\left.\nabla T \cdot \mathbf{n}\right|_{z=z_{\mu}}\right\rangle .
\end{gathered}
$$

The second term on the righthand side equals $\left\langle r_{\mathrm{i}}\right\rangle$ and both disappear. (The equation says then that the heat flux entering the ice at the bed is found again at $z=h_{\mathrm{i}}$.) With reduced variables (in particular $Z_{\mathrm{i}}=c \omega h_{\mathrm{i}}$ ):

$$
\frac{K_{\mathrm{b}}}{K_{\mathrm{i}}} \frac{A \tau_{\mathrm{b}}}{a}\left\langle R_{\mathrm{b}}\right\rangle-\frac{\phi_{\mathrm{g}}}{\rho L}=\frac{A \tau_{\mathrm{b}}}{a} c\left\langle\left.\frac{\partial\left(S_{0}-\Theta\right)}{\partial Z}\right|_{Z=Z_{\mathrm{i}}}\right\rangle .
$$

Since $\left\langle\partial S_{0} / \partial Z\right\rangle=0, Z_{\mathrm{i}}$ is a positive root of

$$
c\left\langle\frac{\partial \Theta}{\partial Z}\right\rangle=\frac{a}{A \tau_{\mathrm{b}}}\left(\frac{\phi_{\mathrm{g}}}{\rho L}\right)-\frac{K_{\mathrm{b}}}{K_{\mathrm{i}}}\left\langle R_{\mathrm{b}}\right\rangle .
$$

It is sufficiently accurate for our needs to use the following approximation:

$$
\begin{aligned}
& \left\langle\frac{\partial \Theta}{\partial Z}\right\rangle \approx \frac{\left\langle\partial\left(\Theta^{2}\right) / \partial Z\right\rangle}{2\left\langle\Theta^{2}\right\rangle^{\frac{1}{2}}} \\
& =\frac{\left\{4 y\left(Z-Z^{2}\right)+(d / 2)\left[2 y-(1+3 y) Z-d Z^{2}\right]\right\} \mathrm{e}^{-2 Z}}{2\left\{\left[4 y Z^{2}+(d / 2)\left(d+2 s Z+d Z^{2}\right)\right] \mathrm{e}^{-2 Z}+(a \omega)^{2}\right\}^{\frac{1}{2}}} .
\end{aligned}
$$

\section{SLIDING VELOCITY, TAKING THE MELTING- REFREEZING PROCESS INTO ACCOUNT}

The fact that on the stoss sides most of the melting occurs within the ice and not against the bed does not impede this melting process to allow in part the surmounting of bumps by sliding ice. Instead of ice disappearing against the stoss face, it disappears mainly within the ice, which contrasts vertically because meltwater cannot accumulate. The only difference with standard sliding theory is that the water migration from stoss sides to lee ones is not by the mythical, never-observed, water film of micrometric thickness between ice and rock, but thanks to wellknown ice permeability.

In Nye's asymptotic solution for impermeable, dry and Newtonian viscous ice sliding on a sine profile, a stream line runs across the crests of all the bumps. The thickness of the regelation ice below is $a_{\mathrm{m}}(1-\cos \omega x)$. The velocity and stress fields are the same as though there were no phase changes, and ice was sliding without friction on the sine profile $z=a_{\mathrm{m}}+a_{\mathrm{v}} \cos \omega x$, with $a_{\mathrm{v}}=a-a_{\mathrm{m}}$. In this case, we have $\eta$ denoting the viscosity, and assuming $K_{\mathrm{b}}=K_{\mathrm{i}}$ (Lliboutry, 1987b, p. 146-49):

$$
\begin{gathered}
\sigma_{z \mu}=\sigma_{\mathrm{b}}+2 \eta U a_{v} \omega^{2} \sin \omega x \\
\quad \text { (from the stress-strain-rat } \\
\frac{\tau_{\mathrm{b}}}{a \omega}=\left\langle\sigma_{z \mu} \sin \omega x\right\rangle \\
\quad \text { (from global equilibrium) }
\end{gathered}
$$$$
\text { (from the stress-strain-rate field) }
$$

$$
r=U a_{\mathrm{m}} \omega \sin \omega x
$$

(from geometry)

$$
r=2 A \omega\left(\sigma_{z \mu}-\sigma_{\mathrm{b}}\right)
$$

(from the standard temperature field).

By eliminating $\sigma_{z \mu}, a_{\mathrm{v}}$ and $a_{\mathrm{m}}$ are obtained, and $a_{\mathrm{v}}+a_{\mathrm{m}}=a$ yields:

$$
U=\frac{\tau_{\mathrm{b}}}{a \omega}\left[\frac{a}{\eta(a \omega)^{2}}+\frac{4 A}{a}\right]=U_{\mathrm{v}}+U_{\mathrm{m}}
$$

The sliding velocity may be split into two parts, corresponding to viscous flow and to melting-refreezing, respectively.

With the new theory, another reasoning holds. The stress field for incompressible ice sliding over $z=a \cos \omega x$ is not modified when internal melting occurs, provided that the contact at the bed is kept. And, this can be ensured by an extra velocity $U_{\mathrm{m}}$. Thus, $U$ given by Equation (19), without changing $a$ is, in fact, $U_{\mathrm{v}}$. It remains to calculate $U_{\mathrm{m}}$.

The accretion rate is no longer proportional to $\sin \omega x$, as resulted from Equations (44.1) and (44.4). It is given by Equation (31), and may be written as a Fourier series:

$$
r=A \frac{\tau_{\mathrm{b}}}{a}\left(R_{0}+R_{1} \sin \omega x+R_{2} \cos \omega x+\ldots\right)-\frac{\phi_{\mathrm{g}}}{\rho L} .
$$

The trend, $A \tau_{\mathrm{b}} R_{0} / a-\phi_{\mathrm{g}} /(\rho L)$, that tilts all the stream lines, may be ignored. Only the leading term in $\sin \omega x$ will be kept. This truncation of the series corresponds to modifying a little the sine-profile model 
Since we do not solve the problem by next writing Fourier integrals in $\omega$, nothing compels us to model a series of bumps by an exact sine curve.

The stress field, and ice fluidity, provide a vertical velocity at the bed $U_{v} a \omega \sin \omega x$. Ice contraction due to internal melting provides an extra vertical velocity $r$. The oscillation of the sum equals the actual oscillation of the vertical velocity at the bed, that is $U a \omega \sin \omega x$. Thus,

$$
\begin{gathered}
U_{m}=\frac{A \tau_{\mathrm{b}} R_{1}}{a^{2} \omega} \\
U=\frac{B}{a \omega}\left(\frac{\tau_{\mathrm{b}}}{1.46 a \omega}\right)^{3}\left[1+7.5(a \omega)^{2}\right] \frac{1}{\omega}+\frac{A \tau_{\mathrm{b}} R_{1}}{(a \omega)^{2}} \omega .
\end{gathered}
$$

Values of $R_{1}$ are given in Table 1 .

\section{REALISTIC VALUES OF THE PARAMETERS AND NUMERICAL RESULTS}

With non-linear rheology, sliding over any micro-relief cannot be solved by summing solutions for each sine component of the micro-relief profile. Therefore, to obtain a realistic sliding law on any bed from theory is very difficult (Lliboutry, 1987a). It is even worse when cavitation must be accounted for, because the behaviour of a sine profile is a singular one, quite different from the behaviour of a series of bumps of unequal heights. Nevertheless, the main prediction of this paper is the existence of an ice-accretion trend $\langle r\rangle$, and of a bottom layer of regelation ice with thickness $h_{\mathrm{i}}$. To estimate their values, the micro-relief model with a sine profile should be sufficient, if the values of $U$ and $\tau_{\mathrm{b}}$, that are related by Equation (47), are realistic. Since there are two parameters in the micro-relief model, one of them has to be arbitrarily fixed.

Since, for given values of $\tau_{\mathrm{b}}$ and $a \omega,\langle r\rangle$ is inversely proportional to $a$, we must consider the smallest bumps existing on the bed for which the theory of locally stresscontrolled temperatures applies. When the bumps are too small, the stress field as given by continuum mechanics varies significantly over distances of the same order as the grain-size $(\sim 1 \mathrm{~cm})$, and this theory is no longer valid. We return to the standard temperature field, which is controlled by the temperatures or heat fluxes at the boundaries of the glacier. Therefore, a wavelength $\lambda=2 \pi / \omega=0.24 \mathrm{~m}$ has been adopted.

The realistic values $\tau_{\mathrm{b}}=1 \mathrm{bar}$ and $K_{\mathrm{b}}=K_{\mathrm{i}}$ have been assumed. $A$ and $B$ are given at the beginning of this paper. Since water forms continuously in bottom ice, the water content should reach its maximum value, about $2 \%$. Therefore, I have adopted $B=1 \mathrm{bar}^{-3} \mathrm{a}^{-1}$, a larger value than the recommended one for the bulk of the glacier: $B=0.44 \mathrm{bar}^{-3} \mathrm{a}^{-1}$ (Lliboutry, 1987b, p. 451). Last, the value $\phi_{\mathrm{g}} /(\rho L)=1 \mathrm{~cm} \mathrm{a}^{-1}$ has been used. It corresponds to a geothermal flux of $2 \mathrm{HFU}$, a standard value for young mountains such as the Alps. Nevertheless, this flux may be locally quite different. It may vanish when meltwater cools the bedrock below the glacier. (This is not mere speculation. In the car tunnel beneath Mont Blanc, cold water pours out, and the ancillary tunnel planned for injecting cool air is actually used to evacuate this water.) The geothermal flux may be larger in deep glacier valleys, because of orographic effects (cf. Forster and Smith, 1989).

The results obtained using these values are given in Table 2.

For high sliding velocities, as for $a \omega=0.1$, there should be cavitation that modifies the stress field in the ice. Nevertheless, the expression that holds without cavitation should remain roughly valid, if we consider $z=a \cos X$ as being the lower boundary of the ice, which includes the ceilings of the cavities. The temperatures $T_{\mu}$ that govern the heat fluxes in the bedrock are constant along the floor of the cavitities, and this floor is no longer $z=a \cos X$. Therefore, $\left\langle R_{\mathrm{b}}\right\rangle$ is somewhat changed but it is a very small term in front of $\left\langle R_{\mathrm{i}}\right\rangle$.

For very slow sliding velocities, as for $a \omega=0.7$, there is no accretion trend, and accordingly Equations (42) and (43) yield no solution for $h_{\mathrm{i}}$. However, strain rates might not be large enough to cause dynamic recrystallization. Then, as reported above, crystals enlarge considerably and $\lambda=24 \mathrm{~cm}$ is too small a value for the theory to be valid. Therefore, in this case $\langle r\rangle=-1 \mathrm{~cm} \mathrm{a}^{-1}$ rather than $-0.66 \mathrm{~cm} \mathrm{a}^{-1}$.

It appears that the internal-melting-ice-accretion effect is important for any sliding velocity greater than

Table 2. Results with $\tau_{\mathrm{b}}=1$ bar, $B=1 \mathrm{bar}^{-3} a^{-1}, \lambda=0.24 \mathrm{~m}, K_{\mathrm{b}} / K_{\mathrm{i}}=1, \phi_{\mathrm{g}} /(\rho L)=1 \mathrm{cma}^{-1}$

aw

0.1

0.2

0.3

1.146

4.07

$U$ (from Equation (47))

$r_{0}=\left(A \tau_{\mathrm{b}} / a\right) R_{0}$

$\left(R_{0}\right.$ from Table 1$)$

$\left.\langle r\rangle=r_{0}-\phi_{\mathrm{g}} / \rho L\right)$

$\langle r\rangle \lambda / U$

$h_{\mathrm{i}}$ (from Equations (42)

and (43))

$h_{\mathrm{w}}$ (from Equation (30))

\subsection{2}

147.1

32.9

31.9

0.52

3.77

19.2

\subsection{4}

13.6

11.5

10.5

1.85

3.67

20.5
5.02

4.02

2.37

3.32

23.0
0.5

0.7 
$1 \mathrm{~m} \mathrm{a}^{-1}$. Between two crests $24 \mathrm{~cm}$ apart, at moderate sliding velocities, the layer of accreted ice thickens by about $2 \mathrm{~mm}$. Internal melting impedes this bottomregelation ice layer to grow infinitely: its thickness $h_{\mathrm{i}}$ stands at $3-4 \mathrm{~cm}$.

Of course, these figures are only rough estimations, because the adopted wavelength, $\lambda=0.24 \mathrm{~m}$ is somewhat arbitrary. The possibility that the best modelling value differs by a factor of 2 cannot be dismissed. Field observations and sample analysis which allow the determination of $h_{\mathrm{i}}$ and $h_{\mathrm{w}}$ might constrain the model better.

\section{CONGLUSION}

Although the consideration of non-linear viscosity and finite amplitudes led to cumbersome hand calculations, it was necessary, because there might have been an objection in that the results yielded by locally stresscontrolled temperatures are totally different in the asymptotic case $a \omega \rightarrow 0$. It has been stated that this is not the case, unless sliding velocities are very small (totally negligible when calculating surface velocities).

The main consequence of considering ice permeability and wetness is the prediction of a bottom layer, some decimetres thick, in which water flows from the stoss sides of decimetric bumps to the lee sides. The main victim of the theory is the popularized concept of a continuous water film between ice and bedrock. Lee cavities (that remain possible) cannot be considered as "thickenings of the water film". It is within this decimetric bottom layer that ions from the bedrock can diffuse into the ice, or migrate to lee faces and provide calcite deposits.

This result is at variance with a previous speculation by Robin (1976), the first person to consider the effect of ice permeability on sliding, for two reasons:

1. There is internal melting even over the lee sides of the bumps. It is not the mean normal pressure in the ice that governs the local ice temperatures but the pressure against the water lenses, which is more or less equal to the maximum compressive stress, and this fact leads to $\nabla^{2} T>0$ near the bed, even over the lee sides.

2. Anyway, because of capillary effects, lenses may freeze without the water in the veins being frozen. Therefore, water can always reach the lee sides of the bumps.

On the other hand, there should be a thinner bottom layer, some centimetres thick, which consists of regelation ice (with possibly small debris picked up from the bed). Since this regelation ice recrystallizes continuously, it cannot be distinguished by its fabric from old ice derived from the firn. The fact that bottom ice is bubble-free is irrelevant, as shown by field evidence. Isotopic studies, as those done by Jouzel and Souchez (1982) would be the only way of checking this prediction.

To check directly the theory of locally stress-controlled temperatures seems almost impossible in the laboratory, because ice creeping steadily during many hours and recrystallizing must be observed. Experiments such as those by Nye and Mae (1972) are not pertinent to this problem. Steady shear of a large ice volume has been obtained by using the huge viscosimeter Penelope (Brepson, 1979; Meysonnier, 1983), but Penelope only worked well at some tenths of a degree below the melting point, using dry ice, and it also took far too much time to open the chamber and retrieve an ice sample.

In situ observations on the walls of a tunnel dug along the bed seem to be more promising. However, they could be obstructed by the fact that temperate-ice properties are of little interest either to industry or climatology. Therefore, to obtain a research grant for the study of such an unusual material becomes quite a problem.

To my knowledge, the only solid material existing in Nature entirely at its melting point, other than ice, is the parent rock from which magma flows towards a magma chamber, a fashionable topic today. Although in melting rocks the melting point is not well defined, this paper might interest volcanologists. Unfortunately, they still ignore the fact that glacier ice is a metamorphic rock, and would be reluctant to call meltwater a magma!

\section{REFERENGES}

Berner, W., B. Stauffer and H. Oeschger. 1978. Dynamic glacier flow model and the production of internal meltwater. Z. Gletscherkd. Glazialgeol., 13(1/2), 1977, 209-217.

Blatter, H. and K. Hutter. 1991. Polythermal conditions in Arctic glaciers. 7. Glaciol., 37(126), 261-269.

Brepson, R. 1979. Simulated glacier sliding over an obstacle. 7. Glaciol., 23(89), 143-156.

Forster, C. and L. Smith. 1989. The influence of groundwater flow on thermal regimes in mountainous terrain: a model study. F. Geophys. Res., 94(B7), 94399451.

Fowler, A.C. 1984. On the transport of moisture in polythermal glaciers. Geophys. Astrophys. Fluid Dyn., 28, 99-140.

Hantz, D. and L. Lliboutry. 1983. Waterways, ice permeability at depth, and water pressures at Glacier d'Argentière, French Alps. F. Glaciol., 29(102), 227239.

Higashi, A. 1978. Structure and behaviour of grain boundaries in polycrystalline ice. 7. Glaciol., $21(85)$, 589-605.

Hutter, K. 1982. A mathematical model of polythermal glaciers and ice sheets. Geophys. Astrophys. Fluid Dyn., 21, 201-224.

Jouzel, J. and R. A. Souchez. 1982. Melting-refreezing at the glacier sole and the isotopic composition of the ice. J. Glaciol., 28(98), 35-42.

Kamb, B. 1970. Sliding motion of glaciers: theory and observation. Rev. Geophys. Space Phys., 8, 673-728.

Lliboutry, L. 1964. Nouveau calcul de la variation du point de fusion sous l'effet des contraintes et application au processus de fonte et regel sous-glaciaire. Comptes-rendus des Séances de l'Académie des Sciences, 258, 1577-1579.

Lliboutry, L. 1971. Permeability, brine content and temperature of temperate ice. 7. Glaciol., 10(58), 1529. 
Lliboutry, L. 1986. A discussion of Robin's "heat pump" effect by extending Nye's model for the sliding of a temperate glacier. Eidg. Tech. Hochschule, Zürich. Versuchsanst. Wasserbau, Hydrol. Glaziol. Mitt. 90, 74-77.

Lliboutry, L. 1987a. Realistic, yet simple bottom boundary conditions for glaciers and ice sheets. $\mathcal{J}$. Geophys. Res., 92(B9), 9101-9109.

Lliboutry, L. 1987b. Very slow flows of solids; basics of modeling in geodynamics and glaciology. Dordrecht, Martinus Nijhoff Kluwer Academic Publishers.

Lliboutry, L. and P. Duval. 1985. Various isotropic and anisotropic ices found in glaciers and polar ice caps and their corresponding rheologies. Annales Geophysicae, 3(2), 207-224.

Means, W. D. and M. W. Jessel. 1986. Accommodation migration of grain boundaries. Tectonophysics, 127, 6786.

Meysonnier, J. 1983. Ecoulement de la glace sur un lit de forme simple: expérience, modélisation, paramétrisation du frottement. (Thèse d'Etat, Université de Grenoble I.)

Montmollin, V. de and 6 others. Unpublished. Teneur en eau de la glace du Glacier d'Argentière. Paper presented at the annual meeting of Société Hydrotechnique de France, section Glaciologie, Grenoble, 12-13 March 1981.

Nye, J. F. 1969. A calculation on the sliding of ice cover over a wavy surface using a Newtonian viscous approximation. Proc. R. Soc. London, Ser. A, 311, 445467.

Nye, J. F. and S. Mae. 1972. The effect of non-hydrostatic stress on intergranular water veins and lenses in ice. $\mathcal{J}$. Glaciol., 11(61), 81-101.

Raymond, C.F. and W.D. Harrison. 1975. Some observations on the behavior of the liquid and gas phases in temperate glacier ice. F. Glaciol., 14(71), 213233.

Robin, G. de Q. 1976. Is the basal ice of a temperate glacier at the pressure melting point? 7 . Glaciol., 16(74), 183-196.

Shoemaker, E. M. 1990. A subglacial boundary-layer regelation mechanism. J. Glaciol., 36(124), 263-268.

Souchez, R. A., R. D. Lorrain and M. M. Lemmens. 1973. Refreezing of interstitial water in a subglacial cavity of an Alpine glacier as indicated by the chemical composition of ice. 7. Glaciol., 12(66), 453-459.

Vallon, M., J. -R. Petit and B. Fabre. 1976. Study of an ice core to the bedrock in the accumulation zone of an Alpine glacier. J. Glaciol., 17(75), 13-28.

The accuracy of references in the text and in this list is the responsibility of the author, to whom queries should be addressed.

\section{APPENDIX I}

\section{VARIATIONAL THEOREM WITH THE COR- RECTED TRIAL STRESS FIELD}

The calculation is done ignoring melting-refreezing processes. Thus, the sliding velocity that is considered is $U_{\mathrm{v}}$ only, not $U$.

A trial stress field is statically admisssible when it obeys the equilibrium conditions (such is the case for any stress field that is defined with an Airy stress function), and the boundary conditions involving stresses. In our case they are: periodicity in $x$, a hydrostatic stress for $z \rightarrow \infty$, and a zero shear stress on $z=a \cos \omega x$. It has been shown that it is approximately the case for:

$$
\chi=-\frac{2 \tau_{\mathrm{b}}}{a \omega^{3}}(1+c \omega z) \mathrm{e}^{-\alpha \omega z} \sin \omega x-\tau_{\mathrm{b}} x z .
$$

Another boundary condition is that for a very large value of $z$, say $z_{\mathrm{M}}$, the forward velocity is:

$$
\left.u\right|_{z=z_{\mathrm{M}}}=U_{v}+B \tau_{\mathrm{b}}^{3} z_{\mathrm{M}} .
$$

Define the dissipation potential:

$$
\Phi_{\mathrm{s}}=\int_{\tau_{i j=0}}^{\tau_{i j}} \dot{\varepsilon}_{i j} \mathrm{~d} \tau_{i j}=\frac{B}{4} \tau^{4}
$$

and a function $\Psi_{\mathrm{t}}$ such that $\partial \Psi_{\mathrm{t}} /\left.\partial \tau_{x z}\right|_{z=z_{\mathrm{M}}}=\left.u\right|_{z=z_{\mathrm{M}}}$ :

$$
\Psi_{\mathrm{t}}=U_{\mathrm{v}} \tau_{\mathrm{b}}+\frac{B}{4} \tau_{\mathrm{b}}^{4} z_{\mathrm{M}} .
$$

Parameters $c$ and $\tau_{\mathrm{b}}$ must be adjusted in order to maximize:

$$
\begin{aligned}
\lambda H_{\mathrm{s}} & =-\int_{0}^{\lambda} \mathrm{d} x \int_{a \cos \omega x}^{z_{\mathrm{M}}} \Phi_{\mathrm{s}} \mathrm{d} z+\int_{0}^{\lambda} \Psi_{\mathrm{t}} \mathrm{d} x \\
& =\lambda U_{\mathrm{v}} \tau_{\mathrm{b}}-\frac{B}{4} \int_{0}^{\lambda} \mathrm{d} x \int_{a \cos \omega x}^{z_{\mathrm{M}}}\left(\tau^{4}-\tau_{\mathrm{b}}^{4}\right) \mathrm{d} z .
\end{aligned}
$$

The upper bound $z_{M}$ may now be made infinite: although the integral of $\tau^{4}$ becomes infinite, the integral of $\left(\tau^{4}-\tau_{\mathrm{b}}^{4}\right)$ remains finite. With the notations in Equation (22), the last Equation (23) reads:

$$
\begin{aligned}
\Theta^{2}=[ & \left.d\left(d+2 s Z+d Z^{2}\right) \sin ^{2} \omega x+4 y Z^{2}\right] \mathrm{e}^{-2 Z} \\
& -4 Z_{\mu} Z e^{-Z}+(a \omega)^{2} .
\end{aligned}
$$

It follows:

$$
\begin{aligned}
\Theta^{4}- & (a \omega)^{4} \\
= & \left\{\left[d^{4}+4 s d^{3} Z+\left(2 d^{4}+4 s^{2} d^{2}\right) Z^{2}\right.\right. \\
& \left.+4 s d^{3} Z^{3}+d^{4} Z^{4}\right] \sin ^{4} \omega x \\
& +\left[8 d^{2} y Z^{2}+16 s d y Z^{3}+8 d^{2} y Z^{4}\right] \sin ^{2} \omega x \\
& \left.+16 y^{2} Z^{4}\right\} \mathrm{e}^{-4 Z} \\
- & Z_{\mu}\left[\left(8 d^{2} Z+16 s d Z^{2}+8 d^{2} Z^{3}\right) \sin ^{2} \omega x+32 y Z^{3}\right] \mathrm{e}^{-3 Z} \\
+ & 16 Z_{\mu}^{2} Z^{2} \mathrm{e}^{-2 Z} \\
+ & (a \omega)^{2}\left[\left(2 d^{2}+4 s d Z+2 d^{2} Z^{2}\right) \sin ^{2} \omega x+8 y Z^{2}\right] \mathrm{e}^{-2 Z} \\
- & 8(a \omega)^{2} Z_{\mu} Z \mathrm{e}^{-Z} .
\end{aligned}
$$

With \langle\rangle denoting a mean value for all $x$ :

$$
\begin{aligned}
H_{\mathrm{s}} & =U_{\mathrm{v}} \tau_{\mathrm{b}}-\frac{B \tau_{\mathrm{b}}^{4}}{4 \omega(a \omega)^{4}} \\
& \cdot \frac{1}{c}\left[\int_{0}^{\infty}\left\langle\Theta^{4}-(a \omega)^{4}\right\rangle \mathrm{d} Z-\left\langle\int_{0}^{Z_{\mu}}\left[\Theta^{4}-(a \omega)^{4}\right] \mathrm{d} Z\right\rangle\right] .
\end{aligned}
$$


The first integral is calculated taking into account that $\left\langle Z_{\mu}\right\rangle=0,\left\langle\sin ^{4} \omega x\right\rangle=3 / 8,\left\langle\sin ^{2} \omega x\right\rangle=1 / 2$, and:

$$
\int_{0}^{\infty} Z^{m} \mathrm{e}^{-p Z} \mathrm{~d} Z=\frac{m !}{p^{m+1}} .
$$

It is found:

$$
\begin{aligned}
I_{1}= & \int_{0}^{\infty}\left\langle\Theta^{4}-(a \omega)^{4}\right\rangle \mathrm{d} Z \\
= & \frac{1}{1024}\left(129 d^{4}+132 s d^{3}+48 s^{2} d^{2}+224 d^{2} y\right. \\
& \left.\quad+192 s d y+384 y^{2}\right)+\frac{(a \omega)^{2}}{4}\left(3 d^{2}+2 s d+16 y\right) \\
= & \frac{1}{1024}\left(45 y^{4}-220 y^{3}+614 y^{2}-364 y+309\right) \\
& \quad+\frac{(a \omega)^{2}}{4}\left(y^{2}+10 y+5\right) .
\end{aligned}
$$

To calculate the second integral, that is a small correction term, the exponentials are developed as a series in $Z$. Several averages are zero and, it is found, to terms in $(a \omega)^{6}$ :

$$
\begin{aligned}
I_{2}= & \left\langle\int_{0}^{Z_{\mu}}\left[\Theta^{4}-(a \omega)^{4}\right] \mathrm{d} Z\right\rangle=\left(2 s d^{3}-2 d^{4}\right)\left\langle Z_{\mu} \sin ^{4} \omega x\right\rangle \\
& +\left(9 s d^{3}-4 s^{2} d^{2}-\frac{14}{3} d^{4}\right)\left\langle Z_{\mu}^{4} \sin ^{4} \omega x\right\rangle \\
& +\left(4 s d y-8 d^{2} y+8 d^{2}-\frac{16}{3} s d\right)\left\langle Z_{\mu}^{4} \sin ^{2} \omega x\right\rangle \\
& -8 y\left\langle Z_{\mu}^{4}\right\rangle+(a \omega)^{2}\left(2 s d-2 d^{2}\right)\left\langle Z_{\mu}^{2} \sin ^{2} \omega x\right\rangle .
\end{aligned}
$$

The averages are easily calculated as:

$$
\begin{aligned}
\left\langle Z_{\mu}^{2} \sin ^{4} \omega x\right\rangle & =(a \omega)^{2} y / 16, \\
\left\langle Z_{\mu}^{4} \sin ^{4} \omega x\right\rangle & =(a \omega)^{4} y^{2}(3 / 128), \\
\left\langle Z_{\mu}^{2} \sin ^{2} \omega x\right\rangle & =(a \omega)^{2} y / 8, \\
\left\langle Z_{\mu}^{4} \sin ^{2} \omega x\right\rangle & =(a \omega)^{4} y^{2} / 16, \\
\left\langle Z_{\mu}^{4}\right\rangle & =(a \omega)^{4} y^{2}(3 / 8),
\end{aligned}
$$

$$
\begin{aligned}
I_{2}=- & \frac{(a \omega)^{2}}{4}\left(y^{5}-3 y^{4}+3 y^{3}-y^{2}\right) \\
& -\frac{(a \omega)^{4}}{128}\left(53 y^{6}-14 y^{5}-\frac{524}{3} y^{4}+606 y^{3}-\frac{259}{3} y^{2}\right) .
\end{aligned}
$$

With the notation:

$$
\begin{aligned}
H_{\mathrm{s}} & =U_{\mathrm{v}} \tau_{\mathrm{b}}-\frac{B \tau_{\mathrm{b}}^{4}}{4 \omega(a \omega)^{4}} V(y) \\
V(y) & =\frac{1}{\sqrt{y}}\left(I_{1}-I_{2}\right)=\frac{P}{1024 \sqrt{y}},
\end{aligned}
$$

the polynomial $P$ reads:

$$
\begin{array}{rl}
P=4 & 5 y^{4}-220 y^{3}+614 y^{2}-364 y-309 \\
& +256(a \omega)^{2}\left(y^{5}-3 y^{4}+3 y^{3}+10 y+5\right) \\
& +8(a \omega)^{4}\left(53 y^{6}-14 y^{5}-\frac{524}{3} y^{4}+606 y^{3}-\frac{259}{3} y^{2}\right) .
\end{array}
$$

The condition $\partial H_{\mathrm{s}} / \partial y=0$ yields the best value for $y$. It is the root of the algebraic equation $2 y P-P^{\prime}=0$.
Next $\partial H_{\mathrm{s}} / \partial \tau_{\mathrm{b}}=0$ gives a lower bound for $\tau_{\mathrm{b}}$ when $U_{\mathrm{v}}$ is given:

$$
U_{\mathrm{v}} \leq \frac{B \tau_{\mathrm{b}}^{3}}{\omega(a \omega)^{4}} V .
$$

Values of $y=c^{2}$ and of the corresponding $V(y)$ are given in Table 3. $V$ increases with $a \omega$ as [1+ $\left.10.9(a \omega)^{2}+0.5(a \omega)^{3}\right]$. Meysonnier's calculations by the finite-element method have shown that $U_{\mathrm{v}}$ increases as $\left[1+7.5(a \omega)^{2}\right]$, but we are dealing with an upper bound for $U_{\mathrm{v}}$. Probably, the upper and lower bounds move away from each other when aw increases.

This lower bound might be found with the complementary variational theorem. Nevertheless, since the dissipation potential is a fractional power of the effective shear strain rate, its integral over the domain cannot be expressed analytically. For this reason, the lower bound was computed only in the asymptotic case $a \omega=0$.

Table 3. Best values of $y=c^{2}$ and corresponding values of $V$, as defined by Equation (I.14)

\begin{tabular}{lcrc} 
aw & $y$ & $V$ & $\left(V-V_{0}\right) /(a \omega)^{2}$ \\
& & & \\
\hline 0 & 0.663361 & $V_{0}=0.33839$ & \\
0.1 & 0.655205 & 0.37547 & 10.96 \\
0.2 & 0.629512 & 0.48746 & 11.01 \\
0.3 & 0.587445 & 0.67595 & 11.08 \\
0.4 & 0.537295 & 0.94209 & 11.15 \\
0.5 & 0.488672 & 1.28644 & 11.21 \\
0.6 & 0.446486 & 1.70948 & 11.26 \\
0.7 & 0.411516 & 2.21202 & 11.30 \\
0.8 & 0.382821 & 2.79504 & 11.34 \\
0.9 & 0.359132 & 3.45961 & 11.39 \\
1.0 & 0.339328 & 4.20680 & 11.43 \\
\hline
\end{tabular}

\section{APPENDIX II}

\section{ZEROS OF THE EFFECTIVE SHEAR STRESS}

For the effective shear stress to be zero, the following conditions must be satisfied:

$$
\begin{gathered}
(s+d Z) \sin X=0 \\
2 c Z \mathrm{e}^{-Z} \cos X=a \omega \\
\left(-180^{\circ}<X \leq 180^{\circ}, \quad Z \geq Z_{\mu}=c a \omega \cos X\right) .
\end{gathered}
$$

The first condition demands either $X=180^{\circ}$, or $X=0^{\circ}$, or $Z=-s / d$.

1. $X=180^{\circ}$. The other conditions read

$$
Z \mathrm{e}^{-Z}=-\frac{a \omega}{2 c}, \quad Z \geq-c a \omega .
$$

Since $Z \leq 0, Z \mathrm{e}^{-Z}$ is an increasing function of $Z$, and

$$
-\frac{a \omega}{2 c} \geq-c a \omega \mathrm{e}^{c a \omega} \text {. }
$$


It follows either $a \omega=0$, or

$$
a \omega \geq-\frac{\ln (2 y)}{\sqrt{y}},
$$

a condition that demands $a \omega \gg 1$, an unrealistic assumption.

2. $X=0^{\circ}$. The conditions read:

$$
Z \mathrm{e}^{-Z}=\frac{a \omega}{2 c}, \quad Z \geq c a \omega .
$$

The function $Z \mathrm{e}^{-Z}$ is a maximum, $\mathrm{e}^{-1}$, for $Z=1$. Thus, when $a \omega=2 c \mathrm{e}^{-1}$, a condition that is met for $a \omega=$ 0.51158 , there is a single zero at $Z=1$. When $a \omega<0.51158$, the equation has two roots, respectively larger and smaller than 1 . Since for $Z<1, Z \mathrm{e}^{-Z}$ increases with $Z$, the latter satisfies the inequality when

$$
\begin{aligned}
& \frac{a \omega}{2 c} \geq c a \omega \mathrm{e}^{-c a \omega} \\
& a \omega \geq \frac{\ln (2 y)}{\sqrt{y}}, \quad \text { or } a \omega=0 .
\end{aligned}
$$

In the former case, the equality is for $a \omega=0.2525$. Then, the zero is at $Z=Z_{\mu}=0.197$.

3. $Z=-s / d$. Putting $s / d=b$, the conditions are

$$
-2 c b \mathrm{e}^{b} \cos X=a \omega, \quad-b \geq a \omega \cos X .
$$

Comparing both, it is found:

$$
a \omega \geq \sqrt{2} b \mathrm{e}^{b / 2} .
$$

The equality is obtained for $a \omega=0.768$. Then

$$
\cos X=-\frac{a \omega}{2 c b} \mathrm{e}^{-b}=-\frac{\mathrm{e}^{-b / 2}}{\sqrt{2} c} .
$$

It is found that $X= \pm 155.2^{\circ}$ and $Z=Z_{\mu}=-0.437$. When $a w$ increases, $\cos X$ decreases down to -1 , which is reached when $a \omega=2 c b e^{b}$. This happens when $a \omega=0.909$ and the zero is at $Z=-0.474>Z_{\mu}$.

\section{APPENDIX III}

\section{ANALYTICAL EXPRESSIONS OBTAINED WITH STRESS FIELD (EQUATION (20))}

\section{Melting rate within the ice}

Its reduced value, as given by Equation (27), is found to be, with notations as in Equation (22):

$$
\begin{gathered}
\left(\frac{\partial^{2}}{\partial X^{2}}+y \frac{\partial^{2}}{\partial Z^{2}}\right)\left(S_{0}-\Theta\right)=-d[(1+3 y)+d Z] \mathrm{e}^{-Z} \sin X \\
+\frac{1}{\Theta^{3}}\left[\mathrm{e}^{-4 Z}\left(P_{2} \sin ^{4} X+P_{1} \sin ^{2} X+P_{0}\right)\right. \\
+\alpha \mathrm{e}^{-3 Z} \cos X\left(Q_{1} \sin ^{2} X+Q_{0}\right) \\
+\alpha^{2} \mathrm{e}^{-2 Z}\left(R_{1} \sin ^{2} X+R_{0}\right) \\
\left.+\alpha^{3} \mathrm{e}^{-Z} \cos X\left(-4-2 d y^{-1} Z\right)\right]
\end{gathered}
$$

with:

$$
\begin{aligned}
P_{2}= & d^{2}\left(1-y+7 y^{2}-3 y^{3}\right)+d^{2}\left(4+2 y+10 y^{3}\right) Z \\
& +d^{3}\left(6+10 y+12 y^{2}\right) Z^{2}+d^{4}(4+6 y) Z^{3}+d^{5} Z^{4} \\
P_{1}=- & 4 y^{2} d^{2}+8 y^{2} d^{2} Z+8 y d\left(1+y+10 y^{2}\right) Z^{2} \\
& \quad-8 y^{2} d\left(-2+5 y+3 y^{2}\right) Z^{3} \\
P_{0}=- & 4 y d^{2} Z^{2}+8 y\left(5 y^{2}-1\right) Z^{3}-4 y\left(1-2 y+5 y^{2}\right) Z^{4} \\
Q_{1}= & -4 y\left(3-2 y+y^{2}\right)-2\left(3+y+5 d y^{2}\right) \\
& \quad-4\left(3-4 y-5 y^{2}+2 y^{3}\right) Z^{2}-2 d\left(1-4 y+y^{2}\right) Z^{3} \\
Q_{0}= & 4 d^{2} Z-8\left(7 y^{2}-1\right) Z^{2}+4\left(1-4 y+7 y^{2}\right) Z^{3} \\
R_{1}= & \left(2 y^{-1}-3+4 y-7 y^{2}\right)-\left(20 y-4 y^{-1}\right) Z \\
& \quad+\left(2 y^{-1}-10 d+6 y^{2}\right) Z^{2} \\
R_{0}= & \left(-y^{-1}+2+23 y\right)-\left(2 y^{-1}+10 y\right) Z \\
& \quad+\left(-y^{-1}+10-y\right) Z^{2} .
\end{aligned}
$$

\section{Heat flux entering the ice}

With non-dimensional variables, the ice-bedrock interface is $Z=Z_{\mu}=\alpha \cos X$, and the mean stress and the effective shear stress at this interface read:

$$
\begin{aligned}
S_{0 \mu}= & \left(s+d Z_{\mu}\right) \mathrm{e}^{-Z_{\mu}} \sin X \\
\Theta_{\mu}=[ & d\left(d+2 s Z_{\mu}+d Z_{\mu}^{2}\right) \mathrm{e}^{-2 Z_{\mu}} \sin ^{2} X \\
& \left.+4 Z_{\mu}^{2}\left(y \mathrm{e}^{-Z_{\mu}}-1\right)+(a \omega)^{2}\right]^{\frac{1}{2}} .
\end{aligned}
$$

The heat flux entering the ice is $-K_{\mathrm{i}} \nabla T \cdot \mathbf{n}=\rho L R_{\mathrm{i}}$, as given by Equation (28). Its reduced value is (with the notation $a \omega \sin X=t)$ :

$$
\begin{aligned}
R_{\mathrm{i}}= & \left.\frac{-1}{\sqrt{1+t^{2}}}\left(c \frac{\partial}{\partial Z}+t \frac{\partial}{\partial X}\right)\left(S_{0}-\Theta\right)\right|_{Z=Z_{\mu}} \\
= & \frac{1}{c \sqrt{1+t^{2}}} e^{-Z_{\mu}}\left\{\left[2 y^{2}-\left(1+y^{2}\right) Z_{\mu}-d Z_{\mu}^{2}\right] \sin X\right. \\
& \left.\quad+\frac{M_{2} \sin ^{2} X+N_{2}}{\Theta_{\mu}}\right\}
\end{aligned}
$$

with:

$$
\begin{aligned}
& M_{2}= d\left[2 y^{2}+s(1-3 y) Z_{\mu}+\left(2+y+y^{2}\right) Z_{\mu}^{2}+d Z_{\mu}^{3}\right] \mathrm{e}^{-Z_{\mu}} \\
& \quad+2 y(a \omega)^{2} Z_{\mu} \\
& N_{2}=2 y\left(Z_{\mu}-Z_{\mu}^{2}\right)\left(2 y \mathrm{e}^{-Z_{\mu}}-1\right) .
\end{aligned}
$$

\section{APPENDIX IV}

\section{ADJUSTMENT OF THE $b_{\mathrm{i}}$ IN EXPRESSION (33) OF BED TEMPERATURES}

The first Equation (35) must be satisfied as far as possible at the 24 points of the bedrock where the variables have been computed. A least-squares criterion has been used. Since $S_{0 \mu}, f_{1}, f_{3}$ are odd functions of $X$ and $\Theta_{\mu}, f_{2}, f_{4}$ are even ones, in the linear set to be solved many terms are zero, and the set splits into the two following:

$$
\left\{\begin{array}{l}
24 b_{0}+b_{2} \sum f_{2}+b_{4} \sum f_{4}=-\sum \Theta_{\mu} \\
b_{0} \sum f_{2}+b_{2} \sum f_{2}^{2}+b_{4} \sum f_{2} f_{4}=-\sum f_{2} \Theta_{\mu} \\
b_{0} \sum f_{4}+b_{2} \sum f_{2} f_{4}+b_{4} \sum f_{4}^{2}=-\sum f_{4} \Theta_{\mu}
\end{array}\right.
$$




$$
\left\{\begin{array}{l}
b_{1} \sum f_{1}^{2}+b_{3} \sum f_{1} f_{3}=\sum f_{1}\left(S_{0 \mu}+\Phi \frac{a \omega Z_{\mu}}{c}\right) \\
b_{1} \sum f_{1} f_{3}+b_{3} \sum f_{3}^{2}=\sum f_{3}\left(S_{0 \mu}+\Phi \frac{a \omega Z_{\mu}}{c}\right) .
\end{array}\right.
$$

Table 4. Adjusted coefficients $b_{i}$, when the temperature field in the bedrock is represented by Equation (33)

With the adopted values $K_{\mathrm{b}}=K_{\mathrm{i}}, \phi_{\mathrm{g}} / \rho L=1 \mathrm{~cm} \mathrm{a}^{-1}$, $\tau_{\mathrm{b}}=1$ bar and $\omega=2 \pi / 0.24 \mathrm{~m}^{-1}$ :

$$
\Phi=\frac{\phi_{\mathrm{g}}}{K_{\mathrm{b}} C_{\mathrm{m}} \tau_{\mathrm{b}} \omega}=0.1785
$$

The second term within the brackets is generally negligible. The values so obtained are given in Table 4 .

$\begin{array}{llllll}a \omega & b_{0} & b_{1} & b_{2} & b_{3} & b_{4}\end{array}$

\begin{tabular}{llllll}
\hline 0 & -0.21309 & 1.66336 & 0 & 0 & 0.14536 \\
0.1 & -0.22258 & 1.65222 & -0.05348 & -0.05074 & 0.14491 \\
0.3 & -0.28733 & 1.67267 & -0.15179 & -0.33046 & 0.21565 \\
0.5 & -0.38728 & 1.64048 & -0.25635 & -0.39366 & 0.25255 \\
0.7 & -0.49276 & 1.57962 & -0.33467 & -0.37520 & 0.23679 \\
\hline
\end{tabular}

MS received 10 February 1992 and in revised form 6 March 1992 